\title{
Unveiling aerosol-cloud interactions - Part 2: Minimising the effects of aerosol swelling and wet scavenging in ECHAM6-HAM2 for comparison to satellite data
}

\author{
David Neubauer $^{1}$, Matthew W. Christensen ${ }^{2,3}$, Caroline A. Poulsen ${ }^{2}$, and Ulrike Lohmann ${ }^{1}$ \\ ${ }^{1}$ Institute for Atmospheric and Climate Science, ETH Zurich, 8092 Zurich, Switzerland \\ ${ }^{2}$ RAL Space, STFC Rutherford Appleton Lab, Harwell, OX11 0QX, UK \\ ${ }^{3}$ Atmospheric, Oceanic and Planetary Physics, University of Oxford, Oxford, OX1 3PU, UK \\ Correspondence to: David Neubauer (david.neubauer@env.ethz.ch)
}

Received: 12 May 2017 - Discussion started: 13 June 2017

Revised: 27 September 2017 - Accepted: 28 September 2017 - Published: 7 November 2017

\begin{abstract}
Aerosol-cloud interactions (ACIs) are uncertain and the estimates of the ACI effective radiative forcing $\left(E F_{a c i}\right)$ magnitude show a large variability. Within the Aerosol_cci project the susceptibility of cloud properties to changes in aerosol properties is derived from the highresolution AATSR (Advanced Along-Track Scanning Radiometer) data set using the Cloud-Aerosol Pairing Algorithm (CAPA) (as described in our companion paper) and compared to susceptibilities from the global aerosol climate model ECHAM6-HAM2 and MODIS-CERES (Moderate Resolution Imaging Spectroradiometer - Clouds and the Earth's Radiant Energy System) data. For ECHAM6HAM2 the dry aerosol is analysed to mimic the effect of CAPA. Furthermore the analysis is done for different environmental regimes.

The aerosol-liquid water path relationship in ECHAM6HAM2 is systematically stronger than in AATSR-CAPA data and cannot be explained by an overestimation of autoconversion when using diagnostic precipitation but rather by aerosol swelling in regions where humidity is high and clouds are present. When aerosol water is removed from the analysis in ECHAM6-HAM2 the strength of the susceptibilities of liquid water path, cloud droplet number concentration and cloud albedo as well as $E F_{a c i}$ agree much better with those of AATSR-CAPA or MODIS-CERES. When comparing satellite-derived to model-derived susceptibilities, this study finds it more appropriate to use dry aerosol in the computation of model susceptibilities.

We further find that the statistical relationships inferred from different satellite sensors (AATSR-CAPA vs. MODIS-
\end{abstract}

CERES) as well as from ECHAM6-HAM2 are not always of the same sign for the tested environmental conditions. In particular the susceptibility of the liquid water path is negative in non-raining scenes for MODIS-CERES but positive for AATSR-CAPA and ECHAM6-HAM2. Feedback processes like cloud-top entrainment that are missing or not well represented in the model are therefore not well constrained by satellite observations.

In addition to aerosol swelling, wet scavenging and aerosol processing have an impact on liquid water path, cloud albedo and cloud droplet number susceptibilities. Aerosol processing leads to negative liquid water path susceptibilities to changes in aerosol index (AI) in ECHAM6-HAM2, likely due to aerosol-size changes by aerosol processing.

Our results indicate that for statistical analysis of aerosolcloud interactions the unwanted effects of aerosol swelling, wet scavenging and aerosol processing need to be minimised when computing susceptibilities of cloud variables to changes in aerosol.

\section{Introduction}

Aerosol particles emitted from natural and anthropogenic sources are important for Earth's climate because of their interactions with radiation and clouds. In particular, the uncertainty of aerosol-cloud interactions is large (Boucher et al., 2013) and impairs the investigation of historical climate records and the prediction of future changes in cli- 
mate. Several studies revealed differences in the response of cloud properties to changes in aerosol optical depth (AOD) in model simulations and satellite observations (e. g. Lohmann and Lesins, 2003; Quaas et al., 2009; McComiskey and Feingold, 2012; Boucher et al., 2013; Schmidt et al., 2015). These differences can be explained by the growth of aerosol particles in the humid environment surrounding clouds (Twohy et al., 2009; Boucher and Quaas, 2012), misclassification of partly cloudy satellite pixels as cloud-free (cloud contamination), brightening of aerosol particles by sunlight reflected at the edge of clouds (3-D-effects; Varnái and Marshak, 2009), processing of aerosol particles in clouds by nucleation or impact scavenging, subsequent growth by heterogeneous chemistry and re-evaporation, wet scavenging of aerosol particles in particular in areas of strong precipitation (Grandey et al., 2014; Gryspeerdt et al., 2015), by stability/humidity changes due to absorbing aerosol above or near clouds, structural uncertainties due to differences in the analysis/observational scale and the process scale (McComiskey and Feingold, 2012), or covariation of aerosol and cloud properties with meteorology (Chen et al., 2014; Andersen et al., 2017). Andersen et al. (2016) showed that cloud droplet size sensitivity to aerosol loading depends on the magnitude of the aerosol loading and that the magnitude of greatest sensitivity is larger for larger total columnar water vapour (with a possible explanation being aerosol swelling). Quaas et al. (2010) identified the swelling of aerosols (Zhao et al., 2017) as the most likely explanation for the larger cloud cover susceptibility (to AOD) in observations than in models. Gryspeerdt et al. (2014) showed that the cloud-top height susceptibility is not a direct response to aerosol changes but mediated by changes in cloud cover (which as the study by Quaas et al. (2010) showed is likely due to covariation of relative humidity). To circumvent the covariation of relative humidity in the cloud cover susceptibility, Gryspeerdt et al. (2016) use the cloud droplet number susceptibility to mediate the cloud cover susceptibility. Thus, cloud cover can only change through a change in cloud droplet number concentration. The mediated cloud cover susceptibilities are much smaller than the "direct" cloud cover susceptibility, hinting at the large influence of other factors like humidity. Bender et al. (2016) used a different approach for analysing albedo-cloud cover histograms. Because of the correlation of cloud cover and AOD they subtract for each cloud cover bin the mean AOD to obtain the correlation of AOD anomalies to the albedocloud cover histograms. After the subtraction they find indications that absorbing aerosol influences the cloud albedo in Namibian and Canarian stratocumulus regions. Boucher and Quaas (2012) and Grandey et al. (2014) used dry AOD to remove the effect of humidity on the susceptibility of the precipitation rate to changes in AOD. However, Koren et al. (2013) showed, with basic hygroscopic growth and radiative transfer calculations, that aerosol swelling alone cannot explain the large difference in AOD in polluted and clean conditions. The algorithm applied to the MODIS (Moderate
Resolution Imaging Spectroradiometer) AOD product that they used filters pixels within $1 \mathrm{~km}$ of detectable clouds, and $25 \%$ of the brightest pixels are rejected within each $10 \times 10 \mathrm{~km}$ aerosol retrieval box. This should significantly reduce the effect of hygroscopic growth and is similar to the minimum distance applied in the Cloud-Aerosol Pairing Algorithm (CAPA) for the AATSR and MODIS products in our study.

The liquid water path (LWP) response to AOD changes also shows a difference between model simulations and satellite observations, such that it is in general larger in model simulations than in satellite observations (Quaas et al., 2009). Although this difference can be explained by similar influences to those in the cloud cover susceptibility, it also depends on the ratio (autoconversion rate/autoconversion rate + accretion rate) of the processes contributing to precipitation formation in global model simulations (Posselt and Lohmann, 2009; Quaas et al., 2009; Gettelman et al., 2015; Sant et al., 2015). We investigate the importance of how precipitation formation is simulated with a prognostic precipitation scheme using prognostic variables for snow, rain and drizzle (Sant et al., 2015). Similarly to the cloud cover susceptibility, the LWP susceptibility (to aerosol changes) is affected by humidity. In the companion paper Christensen et al. (2017) the effects of aerosol swelling, cloud contamination and 3-D-effects are reduced by using a minimum distance between aerosol and cloud observations after screening for contaminated aerosol in the vicinity of clouds. In a global model with coarse resolution a similar approach is not feasible; therefore we evaluate the susceptibilities with respect to dry aerosol, which is similar to CAPA in Christensen et al. (2017). By removing the overshadowing effect of aerosol swelling in the global aerosol-climate model ECHAM6-HAM2, we can also identify other processes influencing the studied susceptibilities.

To study aerosol-cloud interactions in observational data a proxy for cloud condensation nuclei $(\mathrm{CCN})$ is necessary. Liu and $\mathrm{Li}$ (2014) show based on surface measurements that aerosol index (AI) is a better proxy for CCN than AOD and that in situ scattering AI at the surface (i.e. not vertically integrated) has the highest correlation to $\mathrm{CCN}$ at the surface. Stier (2016) has shown using model simulations that vertically resolved measurements of aerosol radiative properties (i.e. as a function of altitude) would be necessary to obtain a good CCN proxy for most of the globe. In the absence of vertical information $\mathrm{AI}$ is considered better as a $\mathrm{CCN}$ proxy than AOD due to the higher weight of smaller aerosols at larger optical depths (Nakajima et al., 2001). Gryspeerdt et al. (2017) showed that including vertical information is beneficial for several global aerosol-climate models, but these benefits are smaller than when using AI instead of AOD as a CCN proxy for most analysed models. The simulations by Stier (2016), Gryspeerdt et al. (2017) and surface measurements do not account for aerosol processing in clouds, which could affect the suitability of these aerosol quantities as a 
CCN proxy. Shinozuka et al. (2015) propose using the in situ dry extinction coefficient and Ångström exponent to parameterise $\mathrm{CCN}$, which accounts for ambient relative humidity, vertical information and aerosol size. Interestingly, in the parameterisation of Shinozuka et al. (2015) the CCNs do not increase linearly with the dry extinction coefficient, which is an indication of growth processes like condensation, coagulation or in-cloud aerosol processing. Aerosol particles can activate as CCN, collide and coalesce with cloud droplets and atmospheric gases can be taken up by cloud droplets and undergo chemical reactions in the aqueous phase. Aerosol particles release by evaporation of cloud droplets or raindrops are larger than before the processing in the clouds. We compare simulations with and without aerosol processing in clouds to obtain an indication of how aerosol processing affects the suitability of different aerosol properties as proxies for $\mathrm{CCN}$.

In Sect. 2 the methodology is outlined and satellite products and model experiments are described in Sect. 3. The results are presented in Sect. 4 and summarised in Sect. 5, where conclusions also are drawn.

\section{Methodology}

For a statistical analysis of aerosol-cloud interactions from satellite data, the data from aerosol and cloud retrievals need to be paired. The Cloud-Aerosol Pairing Algorithm (CAPA), used here for the satellite data, is described in Sect. 2.1. In a model, however, the model parameterisations use the aerosol in a grid box to compute cloud microphysical processes, so the aerosol and cloud data in a grid box match each other all the time due to the model parameterisations, and no further association is necessary. The computation of susceptibilities for the paired aerosol and cloud data from satellite products and the model data is described in Sect. 2.2. As a proxy for $\mathrm{CCN}$, the $\mathrm{AI}$ is used. AI is computed by multiplying AOD by the Ångström exponent (AE). For ECHAM6-HAM2 and the Aerosol_cci products we compute the Ångström exponent from AOD at 550 and $865 \mathrm{~nm}$ (see Sect. 2.3). For the Cloud_cci AATSR products the effective cloud droplet number concentration (CDNC) is derived. By combining Eqs. (6) and (9) from Bennartz (2007) and assuming a cloud fraction $=1, N_{d}$ can be written as

$\mathrm{CDNC}=\frac{1}{2 \pi \cdot k} \cdot \sqrt{\frac{5 \cdot c_{W} \cdot \mathrm{COD}}{Q_{\mathrm{ext}} \cdot \rho_{\mathrm{H}_{2} \mathrm{O}} \cdot R_{\mathrm{e}}^{5}}}=\gamma \cdot \mathrm{COD}^{0.5} \cdot R_{\mathrm{e}}^{-2.5}$,

with

$\gamma=\frac{1}{2 \pi \cdot k} \cdot \sqrt{\frac{5 \cdot c_{W}}{Q_{\mathrm{ext}} \cdot \rho_{\mathrm{H}_{2} \mathrm{O}}}}=1.37 \cdot 10^{-5} \mathrm{~m}^{-0.5}$.

COD is cloud optical depth and $R_{\mathrm{e}}$ is the cloud-top droplet effective radius. Further variables are as defined in Bennartz (2007). Bennartz (2007) discusses the contribution of the variables in Eq. (1) to the uncertainty in CDNC and find that the three input parameters $Q_{\text {ext }}, c_{W}$ and $k$, summarised in $\gamma$, together only account for about $15 \%$ of the total variance in CDNC. Therefore, in the literature often a constant value for $\gamma$ is used. The value for $\gamma$ in Eq. (2) is from Quaas et al. (2006), derived from constants in Brenguier et al. (2000). Equations (1) and (2) assume cloud adiabatic growth. Zeng et al. (2014) compare CDNC computed from the passive sensor MODIS to CDNC from CALISPO depolarisation measurements, which do not rely on the adiabatic assumption (using $r_{\mathrm{e}}$ from MODIS/PARASOL). In regions where clouds grows adiabatically (like stratocumulus regions) the agreement between the two methods is reasonable.

The cloud albedo $(\alpha)$ of ECHAM6-HAM2 is computed from shortwave fluxes at the top of the atmosphere:

$\alpha=\frac{F_{\mathrm{cld}}^{\mathrm{u}}}{F_{\mathrm{cld}}^{\mathrm{d}}}$,

where $F_{\text {cld }}^{\mathrm{u}}$ and $F_{\text {cld }}^{\mathrm{d}}$ denote top of the atmosphere up- and downwelling shortwave fluxes in the cloudy part of the model grid column. As $\alpha$ is calculated from shortwave fluxes the $\alpha$ susceptibility can only be calculated during the day and therefore is computed from fewer aerosol-cloud data pairs than the other susceptibilities (this is only relevant for ECHAM6-HAM2 as the satellite retrievals are done for daylight scenes).

\subsection{Cloud-Aerosol Pairing Algorithm (CAPA)}

CAPA applied to paired aerosol and cloud pixels is described in detail in the companion paper, Christensen et al. (2017). By pairing high-resolution retrievals of aerosol and cloud properties CAPA aims to minimise data aggregation effects at coarser resolution (McComiskey and Feingold, 2012) and provides sufficient data pairs for significant susceptibilities. To reduce cloud contamination, 3-D radiative effects and aerosol swelling, a minimum distance of $15 \mathrm{~km}$ is required between the aerosol and cloud pixels.

\subsection{Susceptibility computation}

Susceptibilities $\left(\mathrm{ACI}_{y}\right)$ are computed at the highest spatial resolution available by linear regression over all aerosolcloud data pairs of a season following Feingold et al. (2003):

$\mathrm{ACI}_{y}=\frac{\mathrm{d} \ln y}{\mathrm{~d} \ln x}=\frac{\sum_{i=1}^{n}\left(\ln x_{i}-\overline{\ln x}\right)\left(\ln y_{i}-\overline{\ln y}\right)}{\sum_{i=1}^{n}\left(\ln x_{i}-\overline{\ln x}\right)^{2}}$
$\sigma_{\mathrm{ACI}_{y}}=$

$$
\sqrt{\frac{\sum_{i=1}^{n}\left(\ln y_{i}-\overline{\ln y}\right)^{2} / \sum_{i=1}^{n}\left(\ln x_{i}-\overline{\ln x}\right)^{2}-\left(\mathrm{ACI}_{y}\right)^{2}}{n-2}},
$$



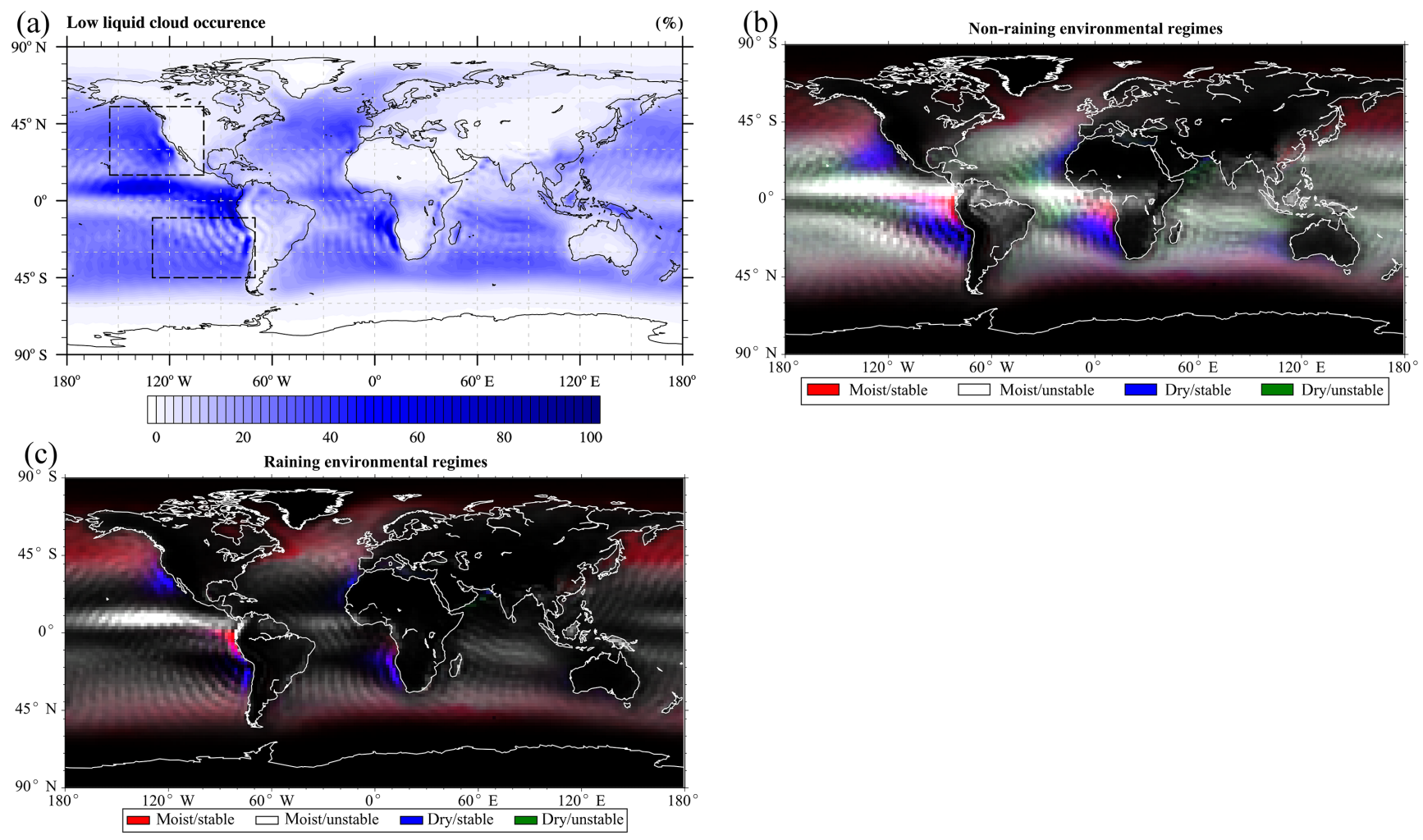

Figure 1. Average frequency of the occurrence of low liquid clouds (cloud-top pressure $>500 \mathrm{hPa}$, cloud-top temperature $>273.15 \mathrm{~K}$ ) in E6_Ref between 1995 and 2012 in (a) for all environmental regimes together, (b) for non-raining regimes, (c) for raining regimes. In (a) are also the two stratocumulus regions where the impact of the analysed regions is assessed.

where $y$ is a cloud property like LWP, and $x$ is an aerosol property like AI. The natural logarithm of $x$ and $y$ is used to make the susceptibilities $\mathrm{ACI}_{y}$ independent of the units used for $x$ and $y$. We require a minimum number of aerosol-cloud data pairs $n \geq 100$ for the computation of the linear regression (for the 12 to 18 years of analysed model data; note that the high-resolution satellite data using CAPA provides many more data pairs). Averages over larger areas and/or longer time spans use the weighted mean method by Grandey and Stier (2010). As weights for each grid point the inverse of the standard deviation of the linear regression given in Eq. (5): $\left(\sigma_{\mathrm{ACI}_{y}}\right)^{-2}$ is used in Grandey and Stier (2010), which makes the weights approximately proportional to the number of aerosol-cloud data pairs $n$ used in the linear regression. As this sigma error weighting could lead to a bias towards regions and seasons with low $1 \sigma$ error, we use the number of aerosol-cloud data pairs $n$ as weights instead:

$\overline{\mathrm{ACI}_{y}}=\frac{\sum_{k=1}^{m} \operatorname{ACI}_{y, k} \cdot n_{k}}{\sum_{k=1}^{m} n_{k}}$
$\sigma_{\overline{\mathrm{ACI}_{y}}}=\sqrt{\frac{\sum_{k=1}^{m}\left(\mathrm{ACI}_{y, k}-\overline{\mathrm{ACI}_{y}}\right)^{2}}{m-1},}$

where $k=1, \cdots, m$ is the index over all susceptibilities $\mathrm{ACI}_{y, k}$ computed at high resolution (e.g. $1^{\circ}$ spatial resolution) in a larger region consisting of $m$ high-resolution grid areas (see Fig. 1 in Grandey and Stier, 2010). Because of the known issues of satellite observations at high zenith angles and over bright surfaces (see e.g. Zygmuntowska et al., 2012), high latitudes $\left(>60^{\circ} \mathrm{N}\right.$ and $\left.>60^{\circ} \mathrm{S}\right)$ have been excluded in this analysis. The analysis is done for eight different environmental regimes defined by the amount of precipitation, humidity in the free troposphere and stability in the lower troposphere and calculated separately for land and ocean. Moist conditions stand for free-tropospheric relative humidity $>40 \%$ and dry conditions for $<40 \%$, stable conditions stand for lower-tropospheric stability $>17 \mathrm{~K}$ and unstable conditions for $<17 \mathrm{~K}$. The lower-tropospheric stability (LTS) is computed as the difference in potential temperature at $700 \mathrm{hPa}$ and the surface:

$\mathrm{LTS}=\theta_{700 \mathrm{hPa}}-\theta_{\text {Surface }}$. 
The free-tropospheric humidity $\left(\mathrm{RH}_{\mathrm{FT}}\right)$ is defined as the average relative humidity between 850 and $700 \mathrm{hPa}$ :

$\mathrm{RH}_{\mathrm{FT}}=\sum_{850 \mathrm{hPa}}^{700 \mathrm{hPa}} \mathrm{RH} / n_{1}$,

where $n_{1}$ is the number of levels between 850 and $700 \mathrm{hPa}$. Raining and non-raining scenes are either differentiated by model precipitation (smaller or larger $0.5 \mathrm{~mm} \mathrm{day}^{-1}$ ), by the CloudSat precipitation flag or by using $R_{\mathrm{e}}$ of $14 \mu \mathrm{m}$ as a proxy for precipitation (Rosenfeld et al., 2014), where $R_{\mathrm{e}}>14 \mu \mathrm{m}$ is a proxy for raining scenes and $R_{\mathrm{e}} \leq 14 \mu \mathrm{m}$ for non-raining scenes. Figure 1 shows the frequency of occurrence of all environmental regimes.

Our analysis uses the pixel-scale (1 km spatial resolution) level 2 Aerosol and Cloud_cci AATSR products. Only data points are analysed where (fully overcast) cloud and aerosol pixels can be paired using CAPA. The AATSR cloud properties therefore represent in-cloud properties. The ECHAM6HAM2 cloud properties are divided by the low liquid cloud cover (cloud-top pressures $>500 \mathrm{hPa}$ and cloud-top temperatures $>273.15 \mathrm{~K}$ ) to obtain in-cloud values also for the global model data. The computation of mean susceptibilities in Eq. (6) uses the number of aerosol-cloud data pairs $n$, which is a subsample of the number of cloudy pixels. The susceptibilities computed by Eq. (6) therefore represent gridmean values (in-cloud ACIs multiplied by $n$ ).

Susceptibilities are computed for each grid area for each season using all available years (e.g. all summer seasons during 1995-2012 for the model data, 2002-2012 for AATSR data and 2006-2010 for MODIS data). Annual mean susceptibilities are computed as a weighted mean from the seasonal susceptibilities.

Multiple linear regression could be used in principle to assess the importance of relative humidity on aerosol-cloud susceptibilities. Due to the non-linear dependence of AOD and cloud properties on relative humidity, the ambient relative humidity would need to be observed with high precision at high resolution (horizontal and vertical). As such highresolution satellite observations of humidity are not available, we therefore use CAPA for AATSR products and remove aerosol water from AOD and AI in ECHAM6-HAM2 data.

\subsection{Aerosol index and dry aerosol}

The AI is computed as the product of AOD and the Ångström exponent (ANG; Ångström, 1964):

$\mathrm{AI}=\mathrm{AOD}_{550} \times \mathrm{ANG}$.

The Ångström exponent is computed from AOD at 550 and $865 \mathrm{~nm}$ :

$\mathrm{ANG}=-\log \left(\mathrm{AOD}_{550} / \mathrm{AOD}_{865}\right) / \log (550 / 865)$.
For the dry-aerosol properties the water taken up by the aerosol particles is removed:

$$
\begin{aligned}
\text { AODdry } & =\mathrm{AOD}-\mathrm{AOD}_{\text {aerosol water }} \\
& =\mathrm{AOD} \times\left(1-\text { volume }_{\text {aerosol water }} / \text { volume }_{\text {total aerosol }}\right) \\
\mathrm{AIdry}= & \text { AODdry }_{550} \times \log \left(\text { AODdry }_{865} / \text { AODdry }_{550}\right) \\
& / \log (550 / 865)
\end{aligned}
$$

$\mathrm{AOD}_{\text {aerosol water is calculated by multiplying }}$ AOD by the volume fraction of aerosol water (volume aerosol water/volume total aerosol $_{\text {). All aerosol }}$ particles are assumed to be spherical in this calculation. The calculation of dry-aerosol properties is done only diagnostically; in the simulations the normal AOD including aerosol water is used.

\subsection{Effective radiative forcing}

The effective radiative forcing due to aerosol-cloud interactions $\left(\mathrm{ERF}_{\mathrm{aci}}\right)$ is estimated from the top of the atmosphere clear-sky albedo $\left(\alpha_{\mathrm{clr}}\right)$ and $\alpha$ following Chen et al. (2014) and Christensen et al. (2017):

$$
\begin{aligned}
& \mathrm{ERF}_{\mathrm{aci}}= \\
& \left(\overline{\mathrm{LCC}_{\mathrm{m}}}\left[\frac{\mathrm{d} \alpha_{\mathrm{clr}}}{\mathrm{d} \ln \mathrm{AI}}-\frac{\mathrm{d} \alpha}{\mathrm{d} \ln \mathrm{AI}}\right]-\overline{\alpha_{\mathrm{clr}}-\alpha} \frac{\mathrm{dLCC}}{\mathrm{d} \ln \mathrm{AI}}\right) \Delta a_{\mathrm{AI}} F_{d},
\end{aligned}
$$

where $\overline{\mathrm{LCC}_{\mathrm{m}}}$ is the annual mean low liquid cloud cover, $\overline{\alpha_{\mathrm{clr}}-\alpha}$ is the annual mean shortwave clear sky minus cloud albedo and $\Delta a_{\mathrm{AI}}=\ln \frac{\mathrm{AI}}{\mathrm{AI}-\mathrm{Al}_{\text {anth }}}$ represents the anthropogenic aerosol increase ( $\mathrm{AI}_{\text {anth }}$ is anthropogenic $\left.\mathrm{AI}\right)$, which is taken from reference model simulations (Neubauer et al., 2014) for ECHAM6-HAM2. Note that $\triangle \mathrm{a}_{\mathrm{AOD}}$ based upon AOD has been used in several studies (e.g. Quaas et al., 2008; Bellouin et al., 2013; Chen et al., 2014); therefore we also compute Eq. (14) as a sensitivity test with $\Delta \mathrm{a}_{\mathrm{AOD}}$ instead of $\Delta a_{\mathrm{AI}} . \mathrm{F}_{d}$ is the mean incoming solar radiation. The methodology of Quaas et al. (2008) separates the total anthropogenic aerosol forcing into the increase in CDNC and hence $\alpha$ at constant LWP (first indirect aerosol effect; Twomey, 1974) and a remainder that encompasses the changes in cloud cover and LWP (second indirect effect; Albrecht, 1989) and possibly other processes and artefacts. In contrast, this methodology separates the total anthropogenic aerosol forcing into the change in cloud cover (called extrinsic forcing) and the changes in $\alpha$ where LWP is allowed to change (called intrinsic forcing).

As a reference forcing for ECHAM6-HAM2, $\mathrm{ERF}_{\text {aci }}$ was also diagnosed for low liquid clouds (cloud-top pressures $>500 \mathrm{hPa}$ and cloud-top temperatures $>273.15 \mathrm{~K}$ ) from simulations with present-day and pre-industrial aerosol emissions. 


\section{Satellite products and model experiment description}

\subsection{Satellite products}

Data for the environmental conditions are taken for both satellite data sets (AATSR and MODIS) from the European Center for Medium-Range Weather Forecast-AUXiliary analysis (ECMWF-AUX) product.

\subsubsection{AATSR Aerosol_cci/Cloud_cci products}

The susceptibilities for the Advanced Along-Track Scanning Radiometer (AATSR) data have been computed with CAPA, described in Christensen et al. (2017), from the ESA Aerosol_cci L2 aerosol products, ORAC V4.01, which are available at $10 \times 10 \mathrm{~km}$ horizontal resolution (Popp et al., 2016) and the ESA Cloud_cci L2 cloud products, ORAC V4.01, which are available at $1 \times 1 \mathrm{~km}$ horizontal resolution (Hollmann et al., 2013). The aerosol and cloud products use a similar optimal estimation algorithm (Thomas et al., 2009; Poulsen et al., 2012) and efforts are made within the Aerosol_cci and Cloud_cci projects to ensure that consistent cloud masking is used in the products. AOD at 550 and $865 \mathrm{~nm}, R_{\mathrm{e}}$, cloud LWP, cloud ice water path, cloud optical thickness, cloud-top pressure, and cloud-top temperature are taken directly from Aerosol_cci and Cloud_cci products and from these additional variables were derived as described in Sect. 2. Ten years of data from 2002 to 2012 are used for computing susceptibilities and forcing estimates.

\subsubsection{MODIS/CERES/CloudSat products}

The A-train satellite products are the same as described in Christensen et al. (2016). The data include CloudSat radar data, CERES (Clouds and the Earth's Radiant Energy System) radiative fluxes and Moderate Resolution Imaging Spectroradiometer (MODIS) level 2 (MYD06) cloud and MODIS (MYD08) aerosol products. The methodology follows Chen et al. (2014). All sensors were matched to the nearest CloudSat footprint. The CloudSat precipitation flag is used to identify raining scenes.

Aerosol data are taken from the gridded MODIS (MYD08) atmospheric product $\left(1^{\circ} \times 1^{\circ}\right)$, which is based on the MYD04 aerosol product at $10 \times 10 \mathrm{~km}$. For the MYD04 aerosol product only those retrieved pixels at $1 \times 1 \mathrm{~km}$ are used that are considered cloud-free (elimination of spatially inhomogeneous $3 \times 3$ pixel groups and of the darkest and brightest $25 \%$ of pixels within $10 \mathrm{~km} \times 10 \mathrm{~km}$ boxes; Remer et al., 2005) in averaging to $10 \times 10 \mathrm{~km}$ resolution to limit cloud contamination. Data for 2006-2010 were used for comparability with Chen et al. (2014). For the sake of brevity these products are referred to as MODIS-CERES (note that the MODIS-CERES forcing data are taken from Chen et al., 2014).

\subsection{ECHAM6-HAM2 experiments}

\subsubsection{Model description}

ECHAM-HAMMOZ is a global aerosol-chemistry climate model of which in this study only the global aerosol-climate model part is used. Two versions of ECHAM-HAM are used because they have different options to treat aerosol-cloud interactions. ECHAM6.1-HAM2.2 (Neubauer et al., 2014), for the sake of brevity referred to as ECHAM6-HAM2, consists of the general circulation model ECHAM6 (Stevens et al., 2013) coupled to the aerosol module HAM2 (Zhang et al., 2012), which includes a size-dependent in-cloud scavenging parameterisation (Croft et al., 2010). ECHAM5.5-HAM, for the sake of brevity referred to as ECHAM5-HAM, consists of the general circulation model ECHAM5 (Roeckner et al., 2003) coupled to the aerosol module HAM (Stier et al., 2005). Some of the model components of ECHAM6-HAM2 and ECHAM5-HAM are similar, although in ECHAM6HAM2 several software errors have been fixed. Both model versions use a two-moment cloud microphysics scheme which solves prognostic equations for both mass mixing ratios and number concentrations of cloud liquid water and cloud ice (Lohmann et al., 2007; Lohmann and Hoose, 2009). The Lin and Leaitch (1997) aerosol activation scheme and the Khairoutdinov and Kogan (2000) autoconversion scheme are used in both model versions as well. A minimum cloud droplet number concentration of $40 \mathrm{~cm}^{-3}$ is used in ECHAM6-HAM2 and $20 \mathrm{~cm}^{-3}$ in ECHAM5-HAM. Also, the Tiedtke (1989) convection scheme with modifications by Nordeng (1994) for deep convection is used in both model versions. Furthermore, in both ECHAM6-HAM2 and ECHAM5-HAM, aerosol effects on convective clouds are not included, but there is a dependence of cloud droplets detrained from convective clouds on aerosol. In order to facilitate the comparability of the numerical experiments of both model versions all simulations were performed with the same resolution, T63 $\left(1.9^{\circ} \times 1.9^{\circ}\right)$ horizontal spectral resolution, using 31 vertical levels (L31).

ECHAM6-HAM2 and ECHAM5-HAM use a 1.5-order turbulence closure scheme with a simplified prognostic equation for turbulent kinetic energy (TKE) (Brinkop and Roeckner, 1995) to compute vertical diffusion (mixing) in the boundary layer.

In the ECHAM6-HAM2 simulation with aerosol processing in stratiform clouds, the scheme from Hoose et al. $(2008 \mathrm{a}, \mathrm{b})$ is applied in order to extend the seven aerosol modes of HAM2 through an explicit representation of aerosol particles in cloud droplets and ice crystals in stratiform clouds. The in-cloud aerosol is represented by five tracers for sulfate, black carbon, organic carbon, sea salt and mineral dust for cloud droplets and ice crystals (see details in Neubauer et al., 2014). ECHAM-HAM in its standard configuration does not track aerosol particles in hydrometeors. In the standard configuration scavenged aerosol particles (by 
nucleation and/or impaction scavenging) are removed from the interstitial aerosol (evaporation of rain or sublimation of snow below cloud base release part of the scavenged aerosol particles back to the atmosphere though), and sulfate produced by heterogeneous chemistry is added to the interstitial aerosol. With the aerosol processing scheme, however, aerosol mass transfers to and from in-cloud aerosol tracers by nucleation and impact scavenging, freezing and evaporation of cloud droplets, and melting and sublimation of ice crystals are tracked. These processes are computed explicitly. Sulfate produced by heterogeneous chemistry is added to the in-cloud sulfate aerosol tracer. Aerosol particles from evaporating/sublimating clouds and precipitation are released to the modes that correspond to their size with the aerosol processing scheme.

In the ECHAM5-HAM simulation with prognostic precipitation, the prognostic precipitation scheme by Sant et al. (2015), which builds on work by Posselt and Lohmann (2008) and Sant et al. (2013), is applied, and in addition to the standard cloud liquid water and cloud ice classes it uses rain, drizzle and snow. For all five water classes (three liquid, two solid) prognostic equations for both mass mixing ratios and number concentrations are solved.

\subsubsection{Experiment description}

The experiment set-up follows the guidelines of the AeroCom aerosol-climate model intercomparison initiative (http: //aerocom.met.no/) phase III on assessing the aerosol indirect effect (https://wiki.met.no/aerocom/indirect). The length of the simulations was 18 years (1995-2012) after 3 months of spin-up to get enough aerosol-cloud data pairs for significant susceptibilities. Present-day (year 2000) greenhouse gas concentrations were used in all simulations. Each experiment uses present-day (year 2000) aerosol emissions from the AeroCom Phase II data set (ACCMIP by Angelika Heil, Martin Schultz and colleagues; see http://aerocom. met.no/emissions.html; Lamarque et al., 2010). The simulations were conducted with sea surface temperatures and sea ice cover fixed to observed values (AMIP simulations). In all simulations winds and temperatures were nudged towards ERA-Interim (Dee et al., 2011) reanalysis. Three-hourly instantaneous output is used. The effect of using $3 \mathrm{~h}$ output and not only output at the time of the satellite overpass is discussed in Appendix A. For cloud-top values (e.g. CDNC) the maximum random overlap assumption is used to compute 2D-fields.

To focus only on warm, liquid clouds in the analysis, model cloud-top pressure and temperature (from the $3 \mathrm{~h}$ instantaneous output) are used to identify low liquid clouds as those with cloud-top pressures greater than $500 \mathrm{hPa}$ and cloud-top temperatures exceeding $273.15 \mathrm{~K}$. The model variables are used for the sampling and environmental regime discrimination for the model data. Minimum and maximum values for aerosol and cloud properties are applied to mimic
Table 1. Minimum and maximum values for aerosol and cloud properties used in this study. AOD is aerosol optical depth, AI is aerosol index, CDNC is cloud droplet number concentration, LWP is liquid water path, COD is cloud optical depth and $R_{\mathrm{e}}$ is cloud droplet effective radius. CDNC and $R_{\mathrm{e}}$ are cloud-top values.

\begin{tabular}{lrr}
\hline Variable & $\begin{array}{r}\text { Minimum } \\
\text { value }\end{array}$ & $\begin{array}{r}\text { Maximum } \\
\text { value }\end{array}$ \\
\hline AOD & 0.01 & 1 \\
AI & 0.02 & 0.6 \\
CDNC $\left(\# \mathrm{~cm}^{-3}\right)$ & 1 & 1000 \\
$\mathrm{LWP}\left(\mathrm{g} \mathrm{m}^{-2}\right)$ & 1 & 1000 \\
$\mathrm{COD}$ & 0.1 & 300 \\
$R_{\mathrm{e}}(\mu \mathrm{m})$ & 1 & 50 \\
\hline
\end{tabular}

the sensitivity of the satellite retrievals and remove unrealistically large values that could influence the linear regression (Table 1). The same conditions (cloud type and environmental conditions) on the selection criteria are used for the satellite analysis (environmental data were taken from the ECMWF-AUX product).

Four experiments were conducted: a reference simulation with ECHAM5-HAM (E5_Ref), a reference simulation with ECHAM6-HAM2 (E6_Ref), a simulation with ECHAM5HAM and the prognostic precipitation scheme (E5_Prog) and a simulation with ECHAM6-HAM2 and the aerosol processing scheme (E6_AProc). The E5_Ref and E5_Prog simulations were run for 12 years (2000-2011) as some input files for this older ECHAM-HAM version were not available for the years 1995-1999 and 2012.

\section{Results}

\subsection{Satellite and model susceptibilities}

\subsubsection{Impact of humidity, wet scavenging and aerosol processing}

In Fig. 2a the annual mean susceptibility of the LWP to changes in AI during 1995-2012 between $60^{\circ} \mathrm{N}$ and $60^{\circ} \mathrm{S}$ is shown. The LWP susceptibility is positive almost everywhere (i.e. an increase in AI leads to an increase in LWP and a decrease in AI leads to a decrease in LWP) and the LWP susceptibility exceeds 0.5 in many areas. In Fig. $2 b$ the same is shown as in Fig. 2a - only AIdry (without aerosol water) was used in the computation of the susceptibility. The effect of removing the water uptake by aerosol is immense. Large parts of the globe now show a negative LWP susceptibility (an increase in AI leads to a decrease in LWP and a decrease in AI leads to an increase in LWP) when AIdry is used. In areas where the LWP susceptibility is positive its magnitude is smaller than in Fig. 2a. AI and AIdry are used as proxies for $\mathrm{CCN}$ in the study of aerosol-cloud relationships. AIdry is better suited due to the water uptake of aerosol par- 
(a)

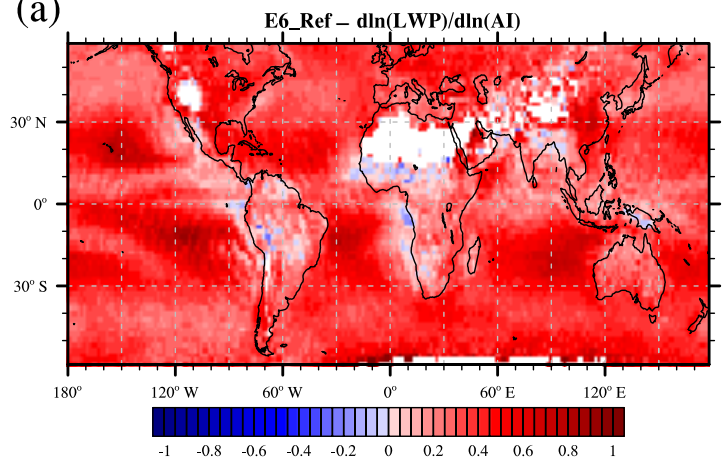

(c)

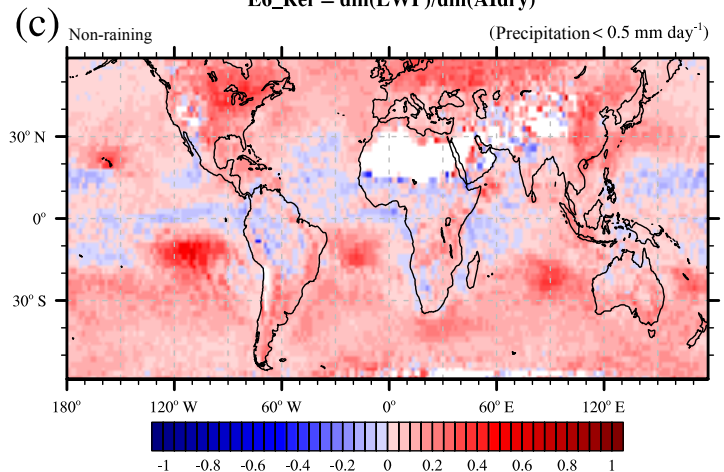

(e)_AProc - dln(LWP)/dln(AIdry)
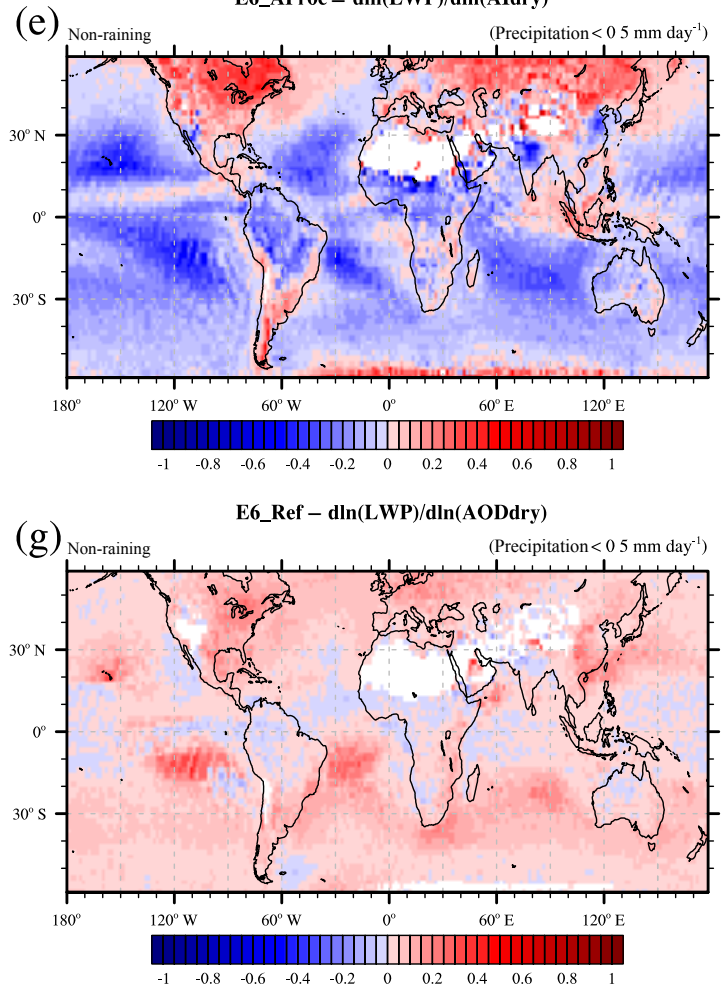

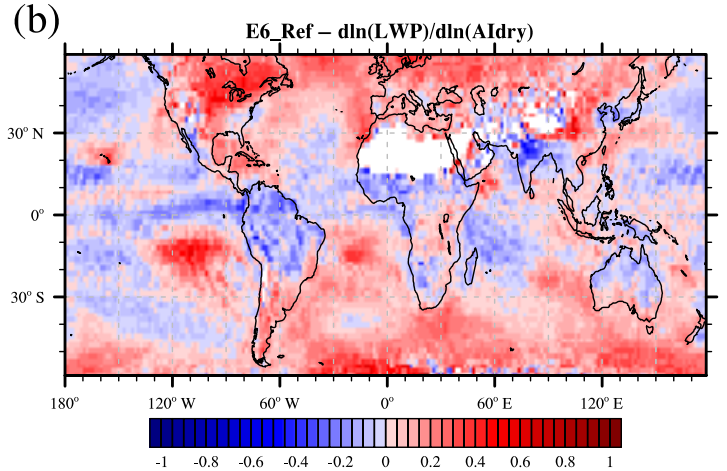

(d) E6_Ref - d dn(LWP)/dln(AIdry)

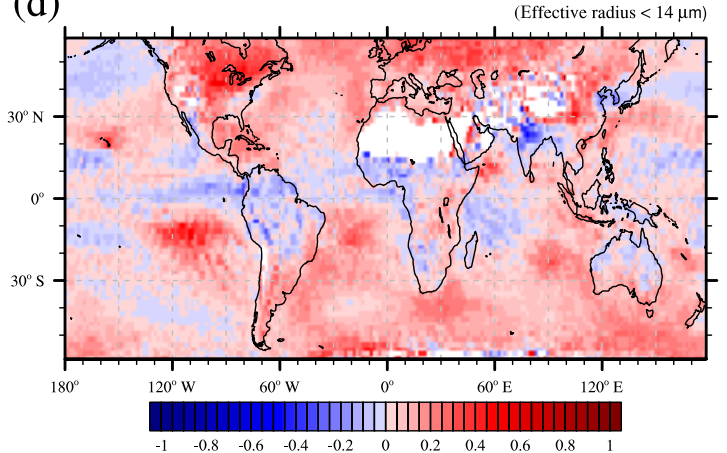

E6_AProc $-\operatorname{dln}(L W P) / \operatorname{dn}($ AODdry)

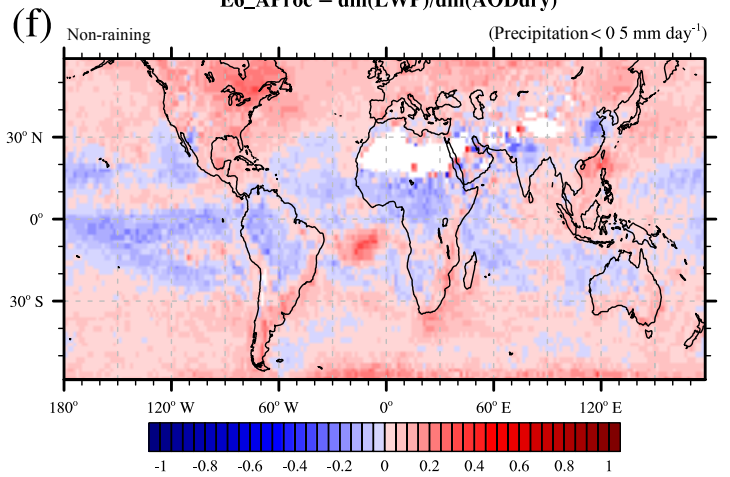

Figure 2. Susceptibility of LWP to changes in AI or AOD for ECHAM6-HAM2 (E6_Ref and E6_AProc) when low liquid clouds and aerosol are present during the simulation period 1995-2012 between $60^{\circ} \mathrm{N}$ and $60^{\circ} \mathrm{S}$. (a) Response in E6_Ref to AI for all scenes, (b) the same as in (a) but for dry AI, (c) same as in (b) but only for non-raining scenes (precipitation $<0.5 \mathrm{~mm} \mathrm{day}^{-1}$ ), (d) same as in (c) but with a different definition for non-raining scenes $\left(R_{\mathrm{e}}<14 \mu \mathrm{m}\right)$, (e) same as in (c) but for E6_AProc, (f) same as in (e) but for dry AOD instead of dry AI, (g) same as in (f) but for E6_Ref. 
ticles in the humid environment close to clouds that affects AI and masks the true effects of the aerosol particles. This covariation with relative humidity is removed when using AIdry. The comparison between Fig. 2a and Fig. 2b shows that the applicability of AI as a CCN proxy is limited by aerosol swelling. Aerosol water uptake in ECHAM6-HAM2 is large, $66 \%$ of the total aerosol mass burden is composed of aerosol water. This is well within the range for water uptake of an AeroCom intercomparison study (Textor et al., 2006) where the multi-model mean and diversity aerosol water mass burden fraction was $48 \% \pm 42 \%$ (excluding one outlier).

To further remove the effects of covarying variables, in Fig. 2c the LWP susceptibility to changes in AIdry is shown only for non-raining scenes. This minimises the effect of wet scavenging of aerosol particles by precipitation but cannot fully remove it (Gryspeerdt et al., 2015). Clouds with higher LWP are more likely to remove aerosol particles by wet scavenging, leading to a negative LWP susceptibility in particular in regions where heavy precipitation occurs frequently. In Fig. 2c the LWP susceptibility is positive everywhere except in regions where deep convection and moderate and heavy precipitation are frequent, so the negative LWP susceptibilities in Fig. 2b seem to be due to wet scavenging. Moderate and heavy precipitation originates predominantly from convective clouds in ECHAM6-HAM2, whereas light precipitation comes mainly from stratiform clouds. In Fig. 2c the LWP susceptibility of precipitating convective clouds is therefore still largely masked by wet scavenging. In Fig. 2a the effect of wet scavenging is not as easily identifiable as in Fig. 2b as the effect of aerosol swelling is overshadowing other factors that influence the statistical relationship of LWP and aerosol such as wet scavenging. In Fig. $2 d$ the same is shown as in Fig. $2 \mathrm{c}$ but using a $R_{\mathrm{e}} \leq 14 \mu \mathrm{m}$ to identify non-raining scenes. This leads to more areas where the LWP susceptibility is negative than in Fig. 2c, but fewer than in Fig. 2b. The differences between Fig. $2 b$ and $c$ may depend on the parameterisations used for precipitation formation (Suzuki et al., 2011) and also the tuning of these parameterisations (Suzuki et al., 2013). Further studies (e.g. with high-resolution models) will be necessary to assess the usability of $R_{\mathrm{e}}$ in a global model as a proxy for precipitation or the absence thereof. In ECHAM6-HAM2 a $R_{\mathrm{e}}$ of $14 \mu \mathrm{m}$ shows deficiencies as a proxy for precipitation state when analysing aerosol-cloud relationships. Stephens et al., 2008 indicate a combination of $R_{\mathrm{e}}$ (>14 $\mu \mathrm{m}$ for rain) and LWP (> $100 \mathrm{~g} \mathrm{~m}^{-2}$ for rain) as a proxy for precipitation state but in ECHAM6-HAM2 this gives similar results to the $R_{\mathrm{e}}$ criterion alone.

Figure 2e shows the same as Fig. 2c but for the simulation with processing of aerosol in stratiform clouds. The LWP susceptibility is negative almost everywhere in Fig. 2e, although only non-raining scenes are shown; i.e. the effect of wet scavenging should be minimal. A possible mechanism that explains the negative LWP susceptibilities is the growth of aerosol particles in cloud droplets (by collisions of the cloud droplets with interstitial aerosol particles and heterogeneous chemistry; Hoose et al., 2008a) and release of the larger aerosol particles when the cloud droplets evaporate (as AIdry decreases for larger particles). The larger the LWP (or cloud lifetime), the more the aerosol may be processed and grow in size in the cloud, therefore leading to negative LWP susceptibilities and to changes in AIdry. A further indication that the negative LWP susceptibility in Fig. $2 \mathrm{e}$ is due to the growth of aerosol particles by aerosol processing is that the LWP susceptibility to changes in AODdry is positive in most regions (see Fig. 2f) even with aerosol processing. AODdry is less sensitive to aerosol size than AIdry, so the negative LWP susceptibility shown in Fig. 2e should rather be due to changes in aerosol size than in aerosol number or mass (for comparison the LWP susceptibility to changes in AODdry of E6_Ref ,i.e. without aerosol processing, is shown in Fig. 2g). It should be noted here that ECHAM6-HAM2 overestimates the lifetime of sea salt particles when aerosol processing is used (Hoose et al., 2008a) and it uses a modal approach to simulate aerosol size and this may be too coarse to well capture the size changes by aerosol processing. Because of these limitations of ECHAM6-HAM2 we use both AI and AIdry as proxies for $\mathrm{CCN}$ in this study. Further research, for example using a bin representation of aerosol size, could give further insight into the effect of aerosol processing on aerosol-cloud interactions.

In Fig. 2a-e the regions over the oceans, where typically shallow convective clouds are present, show a particularly strong LWP susceptibility (positive or negative). Clouds in these regions are not frequent (see Fig. 1a), so these regions do not contribute much to global or regional mean susceptibilities.

Note that the wave structures visible in Fig. 2 and some other figures are due to spurious numerical oscillations (SNOs), which commonly appear in spectral but also in non-spectral models (Geil and Zeng, 2015). The SNOs in Fig. 2 are weaker than in most of the cloud and aerosol input fields (only AIdry and AODdry fields show no SNOs; not shown) and the impact of humidity, wet scavenging and aerosol processing also occurs in regions where there are weak or no SNOs (see Fig. 2), so the results do not seem to be affected by these SNOs.

\subsubsection{Impact of environmental regimes}

To assess the impact of environmental regimes, susceptibilities averaged over all grid boxes of each environmental regime (see Fig. 1b, c) are examined in this section. In the weighted averaging only grid boxes over the global oceans are taken into account.

The response of CDNC to changes in AI (dlnCDNC/dlnAI) averaged over the global oceans is shown in Fig. 3. For ECHAM6-HAM2, AATSR-CAPA and MODIS-CERES, the CDNC susceptibility to AI varies only a little between moist or dry free-tropospheric conditions 

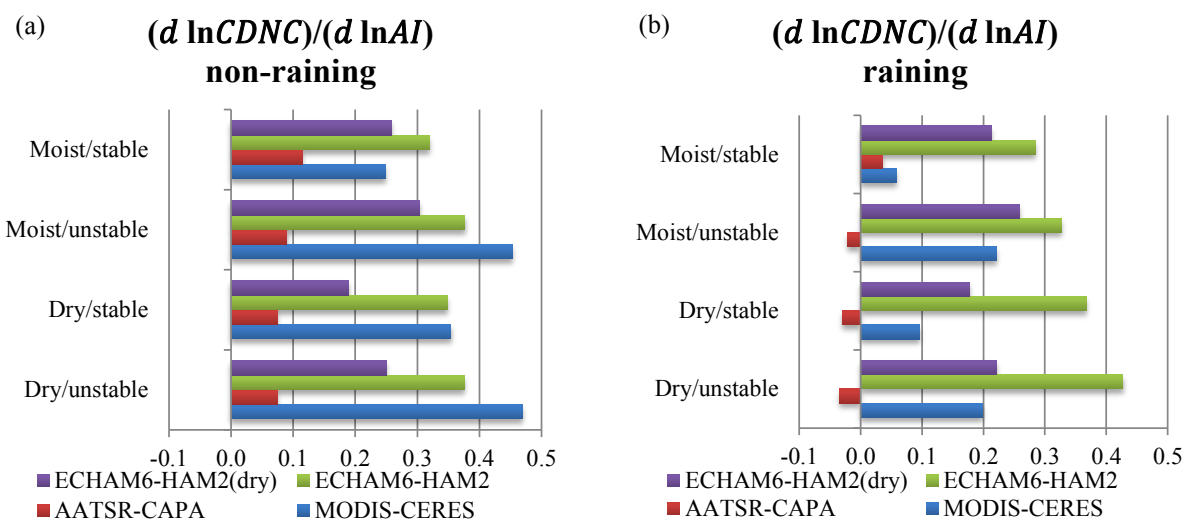

Figure 3. Susceptibility of CDNC to changes in AI for ECHAM6-HAM2 (E6_Ref), E6_Ref without aerosol water uptake (dry) during 1995-2012, for AATSR-CAPA using the full satellite record span 2002-2012 and for MODIS-CERES during 2006-2010. The definitions of the different environmental regimes are given in the text. (a) For all non-raining scenes, (b) for all raining scenes. Only values averaged over global oceans are shown. The MODIS-CERES data are from Christensen et al. (2016).

and a stable or unstable lower troposphere. The CDNC susceptibility of ECHAM6-HAM2 to AIdry is generally smaller, up to $50 \%$ less depending on the regime. The CDNC susceptibility of AATSR-CAPA is smaller than for MODIS-CERES or ECHAM6-HAM2 (AI or AIdry). The minimum distance of the CAPA algorithm should reduce the effects of aerosol swelling, cloud contamination and 3-D radiative effects by selecting aerosols farther away from clouds where these satellite artefacts should be minimal. For AATSR-CAPA this seems to lead to a small CDNC susceptibility. For ECHAM6-HAM2 and MODIS-CERES the differences between non-raining and raining scenes are small and in general the CDNC susceptibility is smaller in the raining scenes than in the non-raining scenes, which is an indication of wet scavenging affecting aerosol concentrations in the raining scenes. For AATSR-CAPA the CDNC susceptibility to AI is smaller in the moist stable regime in the raining than in the non-raining and even negative in the other regimes in the raining scenes, which is also indicative of wet scavenging in the raining scenes. Part of the differences between raining and non-raining scenes may be due to different updraught velocities, which may be higher in the raining than in the non-raining scenes.

The response of LWP to changes in AI (dlnLWP/dlnAI), averaged over the global oceans, shown in Fig. 4, reveals larger susceptibilities and lower variability in susceptibilities between environmental regimes in ECHAM6-HAM2 than in satellite observations. When AIdry is used instead, the magnitude of the LWP susceptibility is close to that of AATSR-CAPA and MODIS-CERES and the variability between environmental regimes in ECHAM6-HAM2 is similar to AATSR-CAPA. In most regimes, the LWP susceptibility to changes in AI or AIdry is larger in the nonraining than in the raining scenes and even negative in some regimes in the raining scenes for AATSR-CAPA, similarly to the CDNC susceptibility. In the non-raining scenes of the
MODIS-CERES data the LWP susceptibility to changes in AI is negative which could be an indication of cloud-top entrainment. Chen et al. (2014) found negative LWP susceptibilities to changes in AI in all environmental regimes for non-raining scenes from MODIS-CERES as shown in Fig. 4. They attribute this to entrainment of dry and warm air from the free troposphere into the boundary layer due to decreased cloud droplet sedimentation of smaller cloud droplets at higher AI. The entrainment is stronger if the free troposphere is drier and/or the lower troposphere is more unstable. Although AATSR-CAPA and MODIS-CERES observed similar scenes, this effect of entrainment seems not to appear in the non-raining scenes in the AATSR-CAPA data. A reason could be the different sampling between AATSR-CAPA and MODIS-CERES, where AATSR has a longer time series and wider swath. The MODIS-CERES data are along the CloudSat nadir-view track. Other differences could be in the retrieval scheme used to obtain cloud and the aerosol properties - ORAC, which uses an optimal estimation method to acquire radiative consistency in the retrieval using all of the channels simultaneously, is compared to MODIS, which uses discrete channel selection to retrieve aerosol and cloud properties (King et al., 1998) separately. The aerosol retrieval has been validated and evaluated within ESA's Aerosol_cci project and a comparable quality of the AATSR and MODIS aerosol retrievals over ocean has been found (Popp et al., 2016). Another reason could be that a $R_{\mathrm{e}}$ of $14 \mu \mathrm{m}$ is not a good proxy for precipitation state of the AATSR data (see Sect. 4.1.1). A reason for the effect of entrainment not seeming to appear in the non-raining scenes in ECHAM6-HAM2 could be that cloud-top entrainment is not well represented in the model. With the TKE scheme used in ECHAM for boundary layer mixing it should in principle be possible to compute cloud-top entrainment when a fine vertical resolution is used. At the coarse vertical resolution of a global climate model numerical artefacts like numerical 

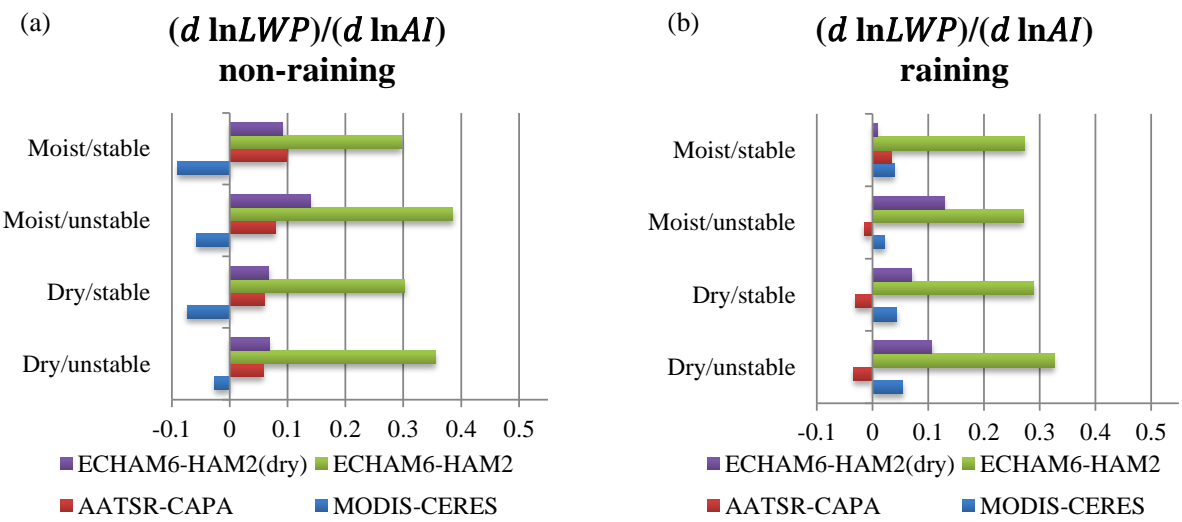

Figure 4. Same as Fig. 3 but for the LWP susceptibility to changes in AI for ECHAM6-HAM2 (E6_Ref), E6_Ref without aerosol water uptake (dry), AATSR-CAPA and MODIS-CERES. The MODIS-CERES data are from Christensen et al. (2016).

entrainment (Lenderink and Holtslag, 2000) occur and the cloud-top cooling that drives the turbulence in the boundary layer cannot be computed accurately (Stevens et al., 1999). A better representation of cloud-top entrainment could act as a buffering mechanism (Stevens and Feingold, 2009) and reduce the LWP susceptibility in ECHAM6-HAM2 in unstable and/or dry regimes. Also, using a prognostic precipitation scheme does not increase the sensitivity to environmental regimes in ECHAM5-HAM (not shown).

In addition to changes in cloud microphysical parameters (CDNC, LWP) it is interesting to investigate the impact of changes in aerosol on a cloud macrophysical parameter like $\alpha$, which is closely related to the effective radiative forcing. The uncertainties in $\alpha$ are better known than for other cloud parameters as fewer assumptions are made in its computation from retrieved cloud properties (Feingold et al., 2016). The susceptibility of $\alpha$ is weaker than the CDNC or LWP susceptibility to changes in AI (AIdry) in both the model and the satellite data (Fig. 5). As for the two other susceptibilities, for the $\alpha$ susceptibility the magnitude of the susceptibility is weaker when aerosol water is eliminated from the analysis (AIdry). Also, the dependence on environmental regime is weak in ECHAM6-HAM2 for the $\alpha$ susceptibility, except for the susceptibility of $\alpha$ to changes in AIdry, which is stronger for the unstable than the stable regimes (see Fig. 5). In the raining scenes the $\alpha$ susceptibility is weaker than in the non-raining scenes or even negative for the moist/stable and dry/unstable regimes $\left(R_{\mathrm{e}}\right.$ increases in these regimes in the raining scenes - not shown). This is another indication that wet scavenging in the raining scenes affects AI and AIdry and that the $\alpha$ susceptibility in the raining scenes not only represents the effect of aerosol on clouds but also the effect (mediated by precipitation) of clouds on aerosol.

\subsubsection{Impact of prognostic precipitation scheme}

For the evaluation of the impact of a prognostic precipitation scheme on aerosol susceptibilities we use the prognostic precipitation scheme developed by Sant et al. (2013), which has recently been implemented in ECHAM5-HAM (Sant et al., 2015) and solves prognostic equations for rain, drizzle and snow. Compared to conventional prognostic precipitation schemes, the additional drizzle class allows a better representation of the drop size distribution and the drizzling conditions that often occur in marine stratocumulus clouds. Previous studies found a shift of precipitation formation from autoconversion to accretion when using a prognostic instead of a diagnostic precipitation scheme, in better agreement with observations (Posselt and Lohmann, 2008; Gettelman and Morrison, 2015). The change to a prognostic precipitation scheme or an autoconversion scheme that depends less on the CDNC results in a smaller effective radiative forcing due to aerosol-radiation and aerosol-cloud interactions $\left(\mathrm{ERF}_{\text {ari }}+\mathrm{aci}\right)$ (Menon et al., 2002; Rotstayn and Liu, 2005, Penner et al., 2006; Posselt and Lohmann, 2009; Gettelman et al., 2015) as accretion is independent of the CDNC. Sant et al. (2015) also find a strong shift of precipitation formation from autoconversion to accretion and a smaller increase of the cloud LWP due to anthropogenic aerosol with their prognostic precipitation scheme. $\mathrm{ERF}_{\text {ari+aci }}$, however, was stronger in its simulation with the prognostic precipitation scheme than with the diagnostic precipitation scheme. In agreement with this increase in $\mathrm{ERF}_{\text {ari+aci }}$ we also find stronger susceptibilities in the E5_Prog simulations compared to E5_Ref as shown in Fig. 6 for the LWP susceptibility (dlnLWP/dlnAI) for E5_Prog, E5_Ref and E6_Ref. The LWP susceptibility in E5_Prog is almost twice as large as in E5_Ref for many environmental regimes for both nonraining and raining scenes. E5_Prog and E5_Ref only differ in the precipitation scheme, in particular in the autoconversion parameterisation, but the models' tuning parameters are the same. 

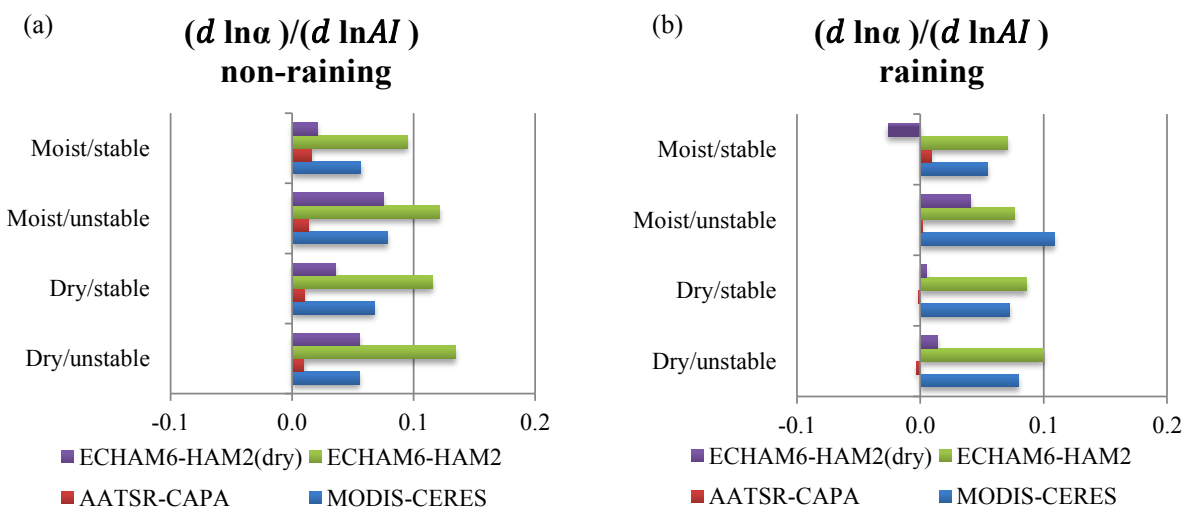

Figure 5. Same as Fig. 3 but for the shortwave cloud albedo susceptibility to changes in AI for ECHAM6-HAM2 (E6_Ref), E6_Ref without aerosol water uptake (dry), AATSR-CAPA and MODIS-CERES. The MODIS-CERES data are from Christensen et al. (2016).
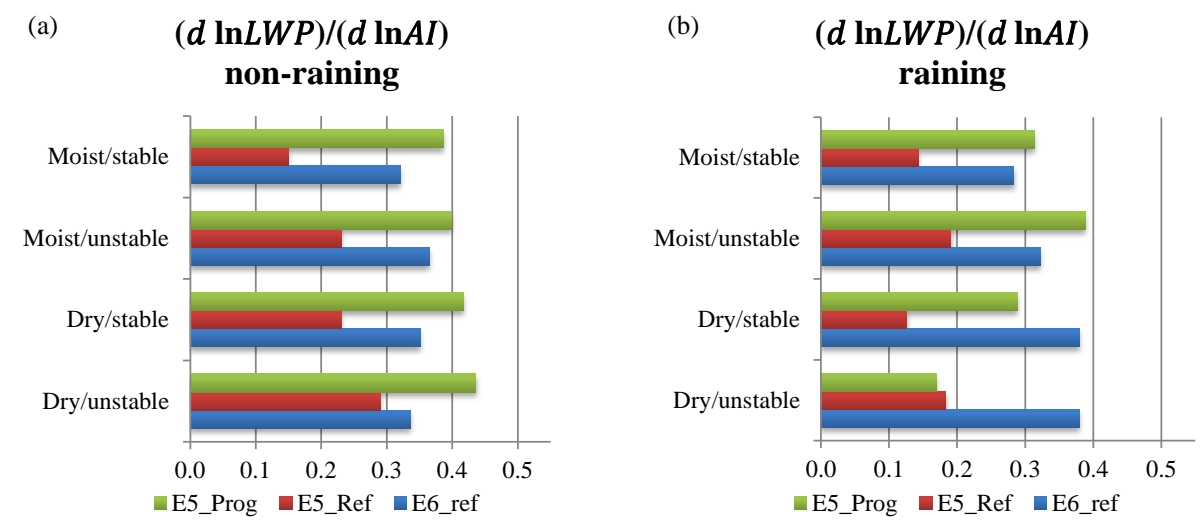

Figure 6. Same as Fig. 3 but for the LWP susceptibility to changes in AI for E5_Prog, E5_Ref and E6_Ref.

A similar increase occurs for other susceptibilities (not shown). There are two reasons for this. First the LWP in stratocumulus regions is higher in E5_Prog than in E5_Ref (Fig. 7b) because of the change in rain (E5_Ref) to drizzle (E5_Prog) in these regions. The increased LWP in E5_Prog (and the increased variability in LWP) seems to increase the (present day) LWP susceptibility in these regions. This is in contrast to the smaller increase in LWP due to anthropogenic aerosol reported in Sant et al. (2015), who computed this increase from simulations with presentday versus pre-industrial aerosol. Carslaw et al. (2013) and Ghan et al. (2016) found that present day variability is a poor proxy for the change due to anthropogenic aerosol for several susceptibilities such as the LWP susceptibility. Our results are similar to their findings as the difference between the prognostic and the diagnostic precipitation scheme leads to a weaker LWP response to anthropogenic aerosols (Sant et al., 2015) but a stronger LWP response determined by present day variability (Fig. 6). Note that covarying variables might affect the LWP susceptibility as well. The other reason for the stronger response of LWP to AI is that AI is larger in E5_Prog than in E5_Ref over the oceans. This leads to a general increase of the susceptibilities. Because AOD is more closely related to the aerosol mass, whereas AI also takes into account the aerosol size, it is instructive to compare AOD and AI in E5_Prog and E5_Ref as it gives an indication whether smaller or larger particles are removed more efficiently by the different precipitation schemes. The AOD is smaller in E5_Prog than in E5_Ref, whereas AI is larger over the oceans in E5_Prog than in E5_Ref (in the global mean AI is similar in E5_Prog and E5_Ref). The prognostic precipitation scheme therefore seems to remove more efficiently larger aerosol particles than the diagnostic precipitation scheme.

These differences between LWP and AI in the simulations have a strong impact on the computed susceptibilities. Global observations with low uncertainty would be necessary to constrain the simulated LWP and AI. Current satellite observations of LWP and AI (e.g. MODIS, AATSR) show considerable differences. Without more observations to better constrain LWP (or other cloud properties) and AI it is not clear which present day simulation (E5_Prog, E5_Ref, E6_Ref) is most realistic and which susceptibilities computed from 
(a)

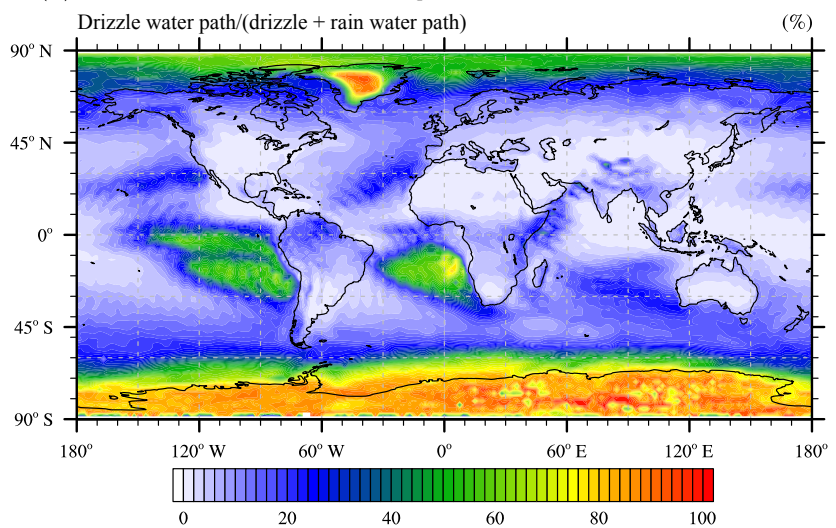

(c)

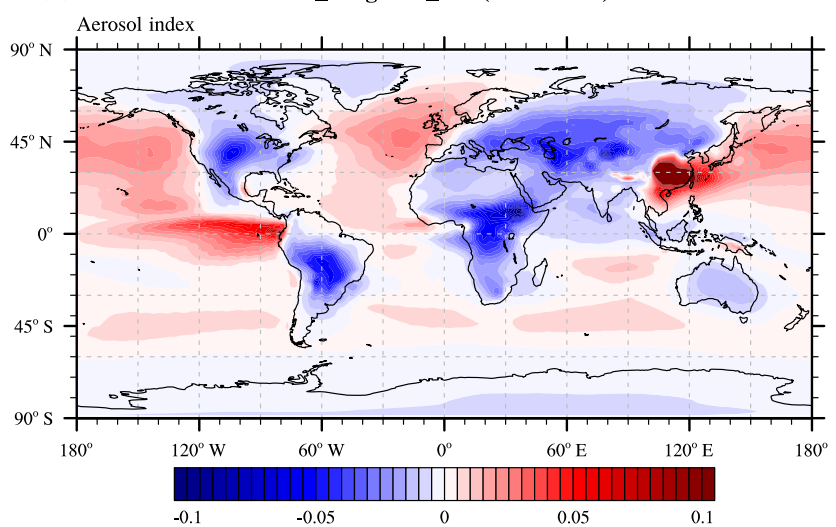

(b)

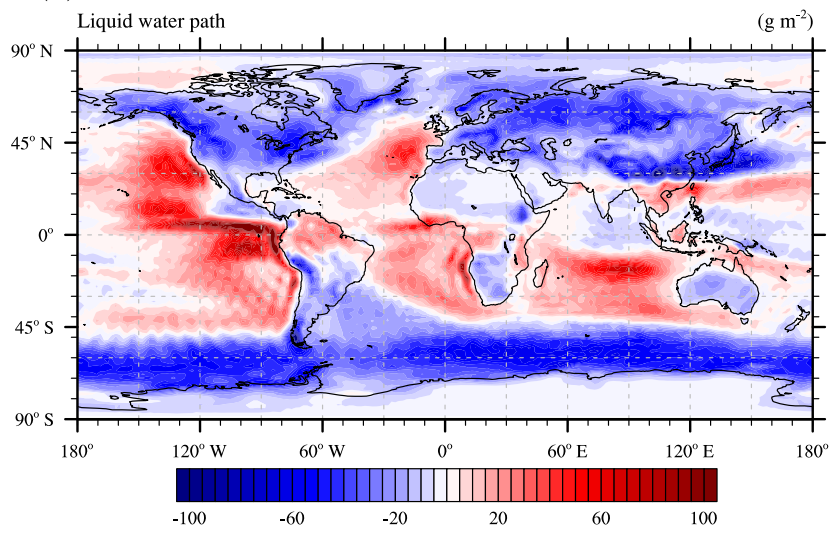

(d)

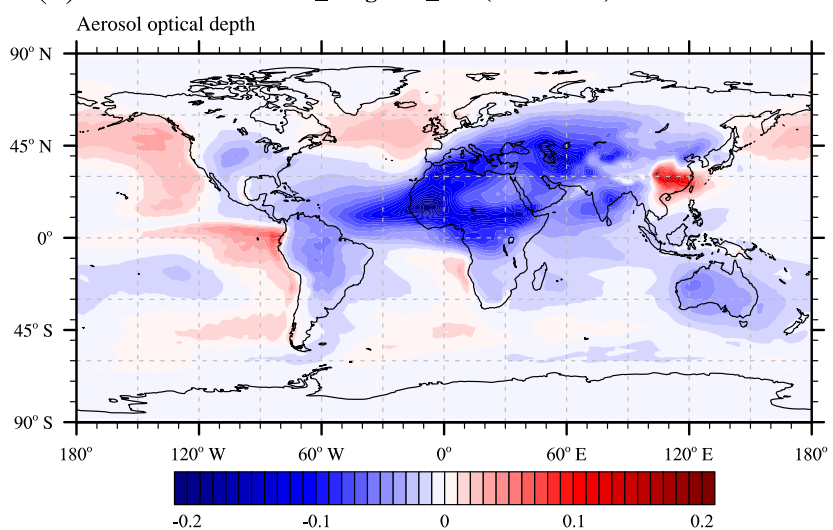

Figure 7. (a) Annual mean ratio of drizzle water path to the sum of drizzle and rain water path for the E5_Prog simulation. The difference between E5_Prog and E5_Ref for 12 years of simulations (2000-2011) (b) LWP, (c) AI, (d) AOD. Panel (a) and (b) include precipitation and LWP from all clouds, not only low liquid clouds, (c) and (d) include cloudy and cloud-free scenes.

these simulations (E5_Prog, E5_Ref, E6_Ref) are most realistic.

\subsubsection{Impact of analysed region}

Because buffering effects of aerosol-cloud interactions can depend on cloud type (Stevens and Feingold, 2009; Christensen et al., 2016) and some areas are also affected by wet scavenging in the non-raining scenes (see Fig. 2c), we compute, in addition to global mean values (between $60^{\circ} \mathrm{N}$ and $60^{\circ} \mathrm{S}$; ocean only), mean values for two stratocumulus regions. The Californian stratocumulus region in the northeastern Pacific $\left(15-55^{\circ} \mathrm{N}, 100-155^{\circ} \mathrm{W}\right)$ and the Peruvian stratocumulus region in the south-eastern Pacific $\left(10-45^{\circ} \mathrm{S}\right.$, $70-130^{\circ} \mathrm{W}$ ), ocean only, are investigated (see Fig. 1a). These are two regions where low liquid clouds and stable environmental regimes are frequent (see Fig. 1) and they are in general less affected by wet scavenging than regions in the tropics (see Fig. 1c). In Fig. 8 the $\alpha$ susceptibility is shown for both stratocumulus regions and all eight environmental regimes. The $\alpha$ susceptibilities of the Californian stratocumulus region are similar to the global $\alpha$ susceptibilities in
Fig. 5, whereas in the Peruvian stratocumulus region they are somewhat stronger for ECHAM6-HAM2. For AATSRCAPA the $\alpha$ susceptibilities are stronger in both stratocumulus regions than globally, whereas for MODIS-CERES the $\alpha$ susceptibilities are similar in both stratocumulus regions and globally. Overall the $\alpha$ susceptibilities in the different analysed regions are qualitatively similar. The previous findings that the susceptibilities are weaker in the raining scenes than in the non-raining scenes and that ECHAM6-HAM2 shows otherwise no strong dependence on the environmental regime are qualitatively the same in the two stratocumulus regions. Similar results were found for the susceptibilities of other cloud properties (not shown). Restricting the analysis to low liquid clouds and the differentiation by environmental regimes therefore seems to be sufficient to separate different cloud types and the differentiation between raining and non-raining scenes seems to minimise the effect of wet scavenging for the non-raining scenes. 


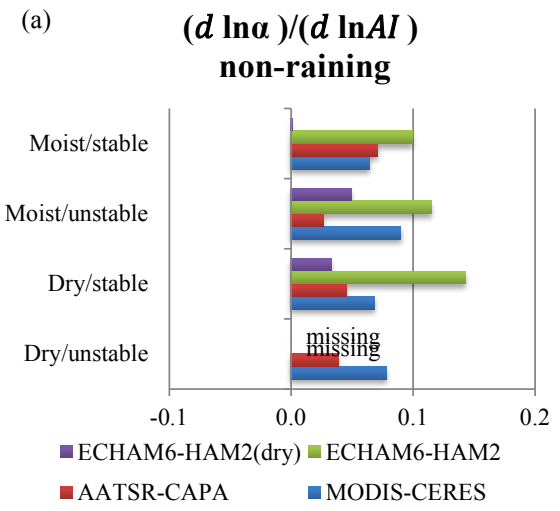

(c)

$$
(d \ln \alpha) /(d \ln A I)
$$$$
\text { non-raining }
$$

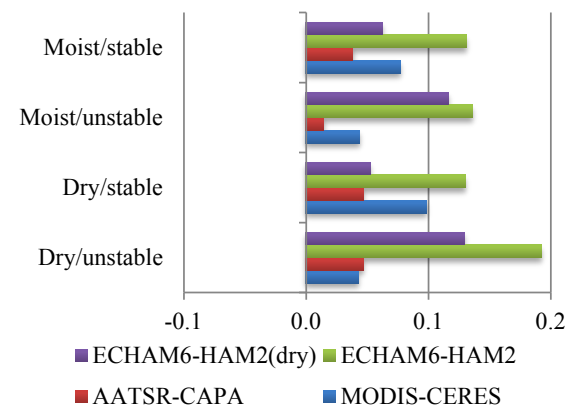

(b)

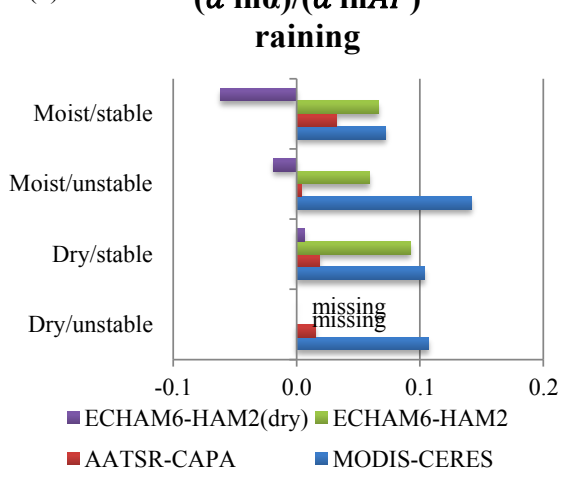

(d)

$(d \ln \alpha) /(d \ln A I)$ raining

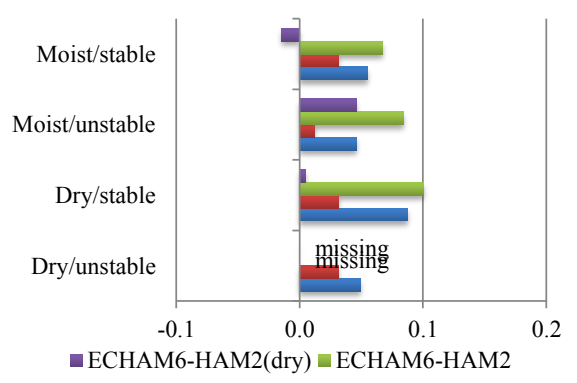

-AATSR-CAPA $\quad$ MODIS-CERES

Figure 8. Same as Fig. 5 but for the shortwave cloud albedo susceptibility to changes in AI for ECHAM6-HAM2 (E6_Ref), E6_Ref without aerosol water uptake (dry), AATSR-CAPA and MODIS-CERES in the (a, b) Californian and (c, d) Peruvian stratocumulus regions. Not enough aerosol-cloud data pairs are available in the stratocumulus regions to make the linear regression significant for the dry/unstable regimes in ECHAM6-HAM2, except for the non-raining scenes in the Peruvian region. The MODIS-CERES data are from Christensen et al. (2016).

\subsection{Effective radiative forcing}

From the susceptibility of $\alpha$ to changes in $\mathrm{AI}$, the $\mathrm{ERF}_{\mathrm{aci}}$ can be estimated. Fig. 9 shows estimates of $\mathrm{ERF}_{\mathrm{aci}}$ for the low liquid clouds over global oceans analysed in this study. For ECHAM6-HAM2, ERF aci was also diagnosed for low liquid clouds from simulations with present day and preindustrial aerosol emissions. The thus-diagnosed forcing of $-0.7 \mathrm{~W} \mathrm{~m}^{-2}$ serves as a reference for ECHAM6-HAM2. Not including aerosol water in the computation of AI leads to a much weaker intrinsic + extrinsic ERF $_{\text {aci }}$ in ECHAM6HAM2 $\left(-0.8 \mathrm{~W} \mathrm{~m}^{-2}\right.$ for all scenes and $-1.5 \mathrm{~W} \mathrm{~m}^{-2}$ for non-raining scenes) in better agreement with the diagnosed reference forcing. The estimates of intrinsic+extrinsic $E^{2} F_{a c i}$ in ECHAM6-HAM2 when aerosol water is included are unrealistically large $\left(-3.5 \mathrm{~W} \mathrm{~m}^{-2}\right.$ for all scenes and $-4.5 \mathrm{~W} \mathrm{~m}^{-2}$ for non-raining scenes), which shows the need to remove aerosol water when computing forcing estimates from present day variability. The results in Ghan et al. (2016) show an underestimation of cloud optical depth and cloud cover susceptibilities computed from present day variability compared to those computed from anthropogenic emissions. Our results for ECHAM6-HAM2 show, in contrast to this, a stronger intrinsic + extrinsic $\mathrm{ERF}_{\mathrm{aci}}$ (based on present day variability) compared to the diagnosed $\mathrm{ERF}_{\mathrm{aci}}$ (based on anthropogenic emissions). A reason for this may be that $\mathrm{AI}$ is a vertically integrated quantity that neither takes the location nor the composition of aerosol particles in the vertical into account (Gryspeerdt et al., 2017).

Not including aerosol water leads to a better agreement of intrinsic ERF $\mathrm{Eci}_{\text {aci }}$ of ECHAM6-HAM2 with estimates of AATSR-CAPA and MODIS-CAPA than when aerosol water is included, but the model still shows considerably larger values of intrinsic $\mathrm{ERF}_{\mathrm{aci}}$ than the satellite estimates. This is an indication of missing or not well-represented processes in ECHAM6-HAM2 like cloud-top entrainment. Intrinsic $\mathrm{ERF}_{\mathrm{aci}}$ is stronger for non-raining scenes compared to the estimates for all scenes, because wet scavenging of aerosol particles by precipitation affects the $\alpha$ susceptibility by removing more aerosols from clouds with a higher $\alpha$ (which are more likely to produce more precipitation) and thereby wet scavenging can lead to a weaker intrinsic $\mathrm{ERF}_{\text {aci }}$ estimate. This indicates that the (strengthening) effect of aerosol swelling on $\alpha$ susceptibility to changes in aerosol is larger than the (weakening) effect of wet scavenging. This makes 

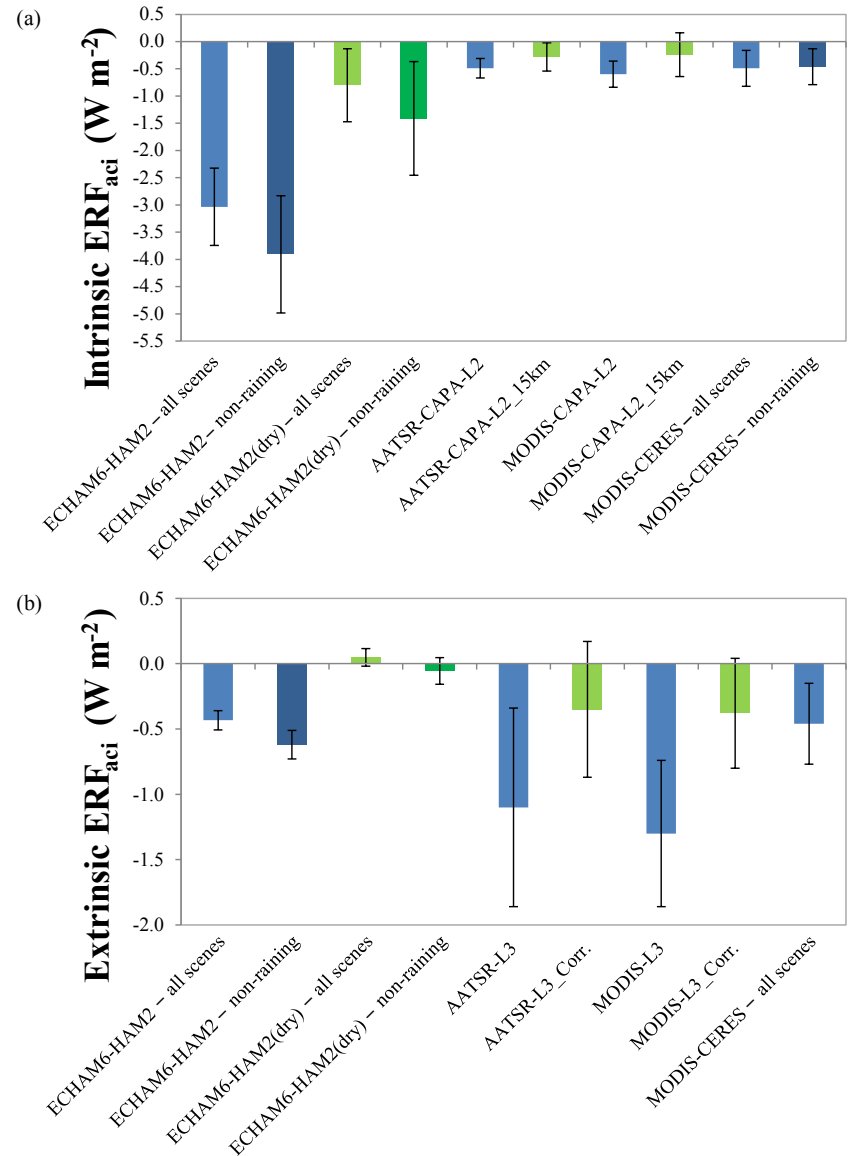

Figure 9. Estimates of (a) intrinsic and (b) extrinsic effective radiative forcing due to aerosol-cloud interactions $\left(\mathrm{ERF}_{\mathrm{aci}}\right)$ of low liquid clouds between $60^{\circ} \mathrm{N}$ and $60^{\circ} \mathrm{S}$. For ECHAM6-HAM2, separate estimates for all scenes and non-raining scenes $\left(<0.5 \mathrm{~mm} \mathrm{day}^{-1}\right)$ as well as with or without aerosol water uptake (dry aerosol) are shown. For AATSR-CAPA and MODIS-CAPA estimates with all aerosol particles (L2/L3) and excluding near-cloud aerosol particles (L2_15 km/L3_Corr.) are shown. Only values averaged over global oceans are shown. The AATSR-CAPA and MODIS-CAPA forcing data are from Christensen et al. (2017). Note that the values for MODIS-CAPA/MODIS-L3/MODIS-L3_Corr. are computed from 3 months' worth of data for June, July and August 2008 only. The MODIS-CERES forcing data are from Chen et al. (2014). The uncertainty is based on the standard error of the linear regression. Light blue bars are used for all scenes with aerosol water uptake or including near-cloud aerosol particles. Green bars indicate removal of aerosol water or near-cloud aerosol particles. Dark bar colours are used for non-raining scenes.

our best estimate for model intrinsic $\mathrm{ERF}_{\mathrm{aci}}$ of $-1.4 \mathrm{~W} \mathrm{~m}^{-2}$ for low liquid clouds over global oceans larger than the satellite data estimates or the diagnosed forcing. For most of the satellite data we only have estimates for all scenes, but they are also likely affected by precipitation (which could even increase the difference in model vs. satellite based estimates). Chen et al. (2014) found slightly less negative values of intrinsic $\mathrm{ERF}_{\text {aci }}$ of MODIS-CERES data for non-raining scenes than for all scenes. This mismatch in model and satellite $\mathrm{ERF}_{\text {aci }}$ estimates could be another indication of missing or not well-represented processes in ECHAM6-HAM2.

The estimates for extrinsic $\mathrm{ERF}_{\mathrm{aci}}$ on the contrary are smaller in ECHAM6-HAM2 than in AATSR-CAPA and MODIS-CAPA and are close to zero for the non-raining scene dry aerosol extrinsic ERF aci estimate in ECHAM6HAM2. The changes in cloud cover are affected by aerosol swelling and other artefacts (Quaas et al., 2010). Indeed the extrinsic $\mathrm{ERF}_{\mathrm{aci}}$ estimates are smaller and even positive for the dry aerosol in ECHAM6-HAM2 and also smaller when excluding near-cloud aerosol in AATSR-CAPA and MODIS-CAPA. Chen et al. (2014) reported that using a smaller horizontal resolution for the analysis than was used in our study for MODIS-CERES leads to a smaller extrinsic $\mathrm{ERF}_{\text {aci }}$ estimate, which may be due to a scale problem (McComiskey and Feingold, 2012).

The considerably larger estimates of intrinsic and extrinsic $\mathrm{ERF}_{\text {aci }}$ in ECHAM6-HAM2 when aerosol water is included compared to previous studies (e.g. Quaas et al., 2008; Bellouin et al., 2013; Chen et al., 2014) are likely due to the use of different variables for the anthropogenic aerosol increase (i.e. AOD vs. AI). We recomputed $\mathrm{ERF}_{\text {aci }}$ using $\Delta \mathrm{a}_{\mathrm{AOD}}(17 \%$ increase in global annual mean from preindustrial aerosol) instead of $\Delta a_{\mathrm{AI}}$ (44\% increase in global annual mean from pre-industrial aerosol). The estimates of intrinsic + extrinsic $\mathrm{ERF}_{\mathrm{aci}}$ in ECHAM6-HAM2 are then much smaller $\left(-1.1 \mathrm{~W} \mathrm{~m}^{-2}\right.$ for all scenes and $-1.2 \mathrm{~W} \mathrm{~m}^{-2}$ for non-raining scenes when aerosol water is included and $-0.3 \mathrm{~W} \mathrm{~m}^{-2}$ for all scenes and $-0.4 \mathrm{~W} \mathrm{~m}^{-2}$ for non-raining scenes when aerosol water is removed). This shows how important it is which variable is used to compute the anthropogenic aerosol increase (as anthropogenic aerosol particles are on average smaller than natural aerosol particles). This is in agreement with results of Gryspeerdt et al. (2017). Their Fig. $3 \mathrm{a}$ and $\mathrm{b}$ also indicates much weaker values for the anthropogenic aerosol increase computed from AOD than from $\mathrm{AI}$ or other proxies for the increase in CDNC.

\section{Summary and conclusions}

It has been recognised in the scientific community that the statistical analysis of aerosol-cloud interactions can be affected by artefacts like cloud contamination or 3-Deffects, by covariations with relative humidity, by effects of clouds on aerosols like wet scavenging or aerosol processing, by absorbing aerosols or by differences in the analysis/observational scale and the process scale. Aerosol swelling has further been identified as the most likely reason for the large cloud cover susceptibility to changes in aerosol in satellite observations. Whereas the effect of aerosol swelling on the cloud cover and precipitation rate susceptibilities and how to minimise it has received atten- 
tion in the literature, the effect on susceptibilities of other cloud variables is less explored. Our results with the global aerosol-climate model ECHAM6-HAM2 show that the LWP and $\alpha$ and to a smaller extent also the CDNC susceptibilities to changes in aerosol are affected by aerosol swelling. By removing aerosol water (and therefore aerosol water uptake) from the computation of susceptibilities, the susceptibilities are considerably reduced and the "dry" susceptibilities agree better with those from AATSR-CAPA and MODIS-CERES. For AATSR satellite data the effect of aerosol swelling is minimised by CAPA with a minimum distance between aerosol and cloud pixel. The MODIS AOD algorithm also uses a minimum distance between aerosol and cloud pixels and removes $25 \%$ of the brightest pixels. Although the hygroscopic growth of aerosols cannot be completely suppressed in the satellite data, because it is non-linear we argue that when comparing it to satellite data that minimise aerosol swelling it is better to use the dry aerosol from model simulations than the wet aerosol.

Our results show further that, in addition to aerosol swelling, wet scavenging and aerosol processing have an impact on LWP, $\alpha$ and CDNC susceptibilities. A separation of raining and non-raining scenes minimised the effect of wet scavenging for the non-raining scenes. For ECHAM6HAM2 this separation was based on model precipitation as $R_{\mathrm{e}}$ alone is not a good proxy for the precipitation state when analysing aerosol-cloud interactions in ECHAM6-HAM2. Aerosol processing leads to negative LWP susceptibilities due to changes in AI in ECHAM6-HAM2, likely due to aerosol-size changes by aerosol processing. This calls for further research on the effect of aerosol processing when analysing the effects of changes in $\mathrm{CCN}$ on cloud properties.

A simulation with prognostic precipitation (rain, drizzle and snow) scheme in ECHAM5-HAM showed that the large LWP susceptibility cannot be explained by overemphasising autoconversion instead of accretion (Sant et al., 2015). While using a prognostic precipitation scheme considerably reduces the ratio of autoconversion to autoconversion + accretion compared to a diagnostic precipitation scheme, it still leads to a large LWP susceptibility because the prognostic drizzle causes higher LWP and AI (variability) in stratocumulus regions compared to the diagnostic precipitation scheme.

A differentiation of susceptibilities by different environmental regimes (precipitation, stability in the lower troposphere, $\mathrm{RH}$ in the lower free troposphere) revealed that AATSR-CAPA, MODIS-CERES and ECHAM6-HAM2 do not always agree in their dependence on environmental regimes. The susceptibility of liquid water path is negative in non-raining scenes for MODIS-CERES but positive for AATSR-CAPA (and ECHAM6-HAM2). A negative LWP susceptibility in non-raining scenes has been interpreted as cloud-top entrainment (Chen et al., 2014). Feedback processes such as cloud-top entrainment that are missing or not well represented in ECHAM6-HAM2 are therefore not well constrained by the satellite observations. Further research with multiple satellite aerosol and cloud products could help to better understand such feedback processes and provide better constraints for climate models.

Data availability. The Centre for Environmental Data Analysis (CEDA; http://www.ceda.ac.uk, ESA, 2014) provided the AATSR satellite data and NASA Goddard (https://ladsweb.nascom.nasa.gov) provided the MODIS satellite data used in this study. Model data are available from David Neubauer (david.neubauer@env.ethz.ch). 


\section{Appendix A: Sampling effects}

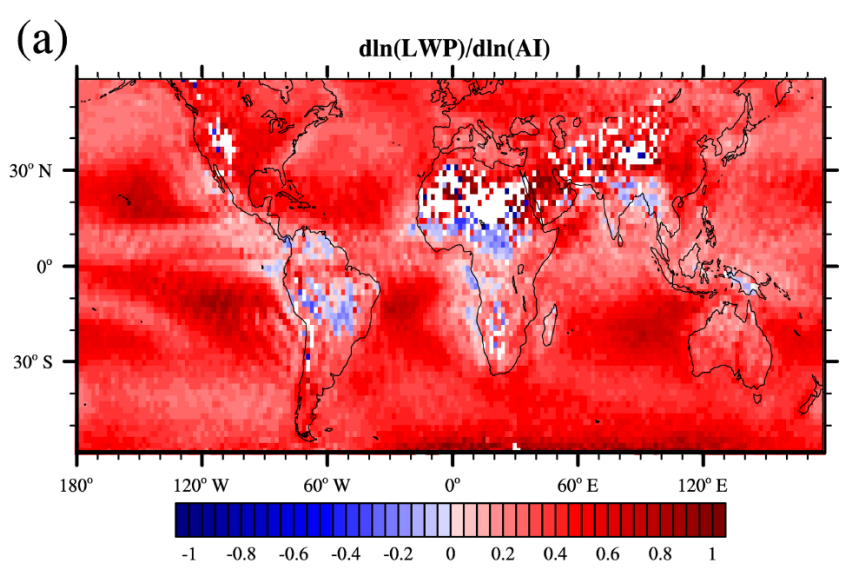

Figure A1. LWP response to changes in AI for ECHAM6-HAM2 sampling.

AATSR observations are done at a mean local solar time of 10:30, while for ECHAM6-HAM2 $3 \mathrm{~h}$ instantaneous data are used. For ECHAM6-HAM2 data, therefore, the diurnal cycle of clouds and aerosol are resolved, while AATSR data are always available at the same time. Resolving the diurnal cycle or not can potentially lead to a difference in the computed susceptibilities. To estimate the effect of the different sampling frequencies and lack of temporal collocation (Schutgens et al., 2016), we compute the LWP susceptibility to changes in AI of a 17-year ECHAM6-HAM2 simulation once from $3 \mathrm{~h}$ output and once from data at 10:30, temporally collocated with AATSR. The results are shown in Fig. A1. The maxima and minima of the LWP susceptibility are more pronounced with the 10:30 local time sampling than with the $3 \mathrm{~h}$ sampling. The general geographical pattern and magnitude of the LWP susceptibility are quite similar for the two sampling methods. As the global ECHAM6-HAM2 simulations have to use a relatively coarse resolution (T63, $1.9^{\circ} \times 1.9^{\circ}$ ), high temporal sampling is necessary to obtain enough aerosol-cloud data pairs to compute significant linear regressions, particularly as we differentiate environmental regimes to compute susceptibilities at the native model grid to reduce effects of aggregation (Grandey and Stier, 2010; McComiskey and Feingold, 2012). As the benefits of the analysis of different environmental regimes with reduced aggregation effects outweigh the difference due to resolving the diurnal cycle or not and the lack of temporal collocation, we have chosen the $3 \mathrm{~h}$ instantaneous data for our analysis.

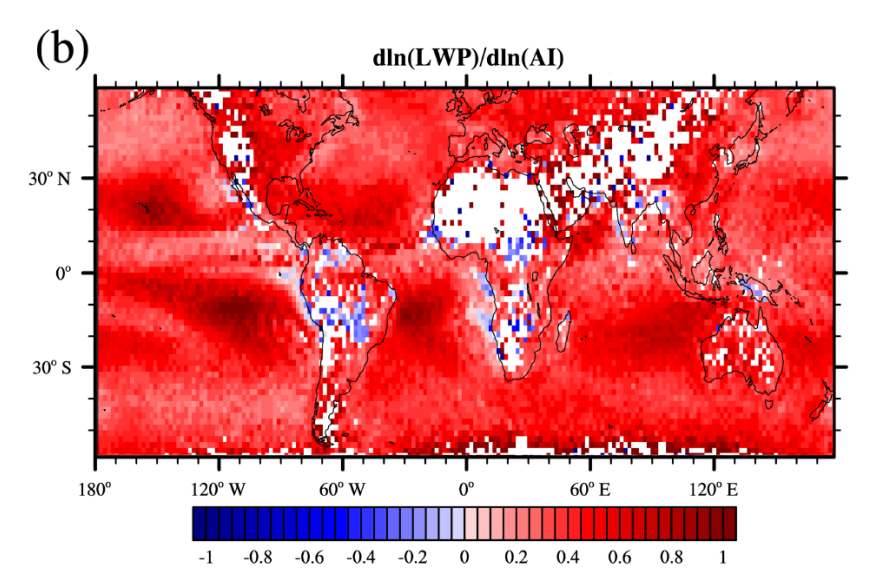
(1995-2011). (a) For $3 \mathrm{~h}$ sampling, (b) for daily (10:30 local time) (a) For 3 h sampling, 


\section{The Supplement related to this article is available online at https://doi.org/10.5194/acp-17-13165-2017- supplement.}

Author contributions. DN designed the analysis, conducted the simulations and computed susceptibilities for ECHAM-HAM and computed the effective radiative forcing estimates. MC computed susceptibilities for MODIS-CERES and MODIS-CAPA. CP provided support needed to run ORAC. UL contributed to the analysis and interpretation of findings. DN prepared the manuscript with contributions from co-authors.

Competing interests. The authors declare that they have no conflict of interest.

Acknowledgements. This work was supported by the European Space Agency as part of the Aerosol_cci project (ESA Contract No. 4000109874/14/I-NB). We thank the ESA Cloud_cci project for providing the cloud satellite data. The MODIS satellite data used in this study were acquired from NASA Goddard (https://ladsweb.nascom.nasa.gov). The ECHAM-HAMMOZ model is developed by a consortium composed of ETH Zurich, Max Planck Institut für Meteorologie, Forschungszentrum Jülich, University of Oxford, the Finnish Meteorological Institute and the Leibniz Institute for Tropospheric Research, and managed by the Center for Climate Systems Modeling (C2SM) at ETH Zurich. The Center for Climate Systems Modeling (C2SM) at ETH Zurich is acknowledged for providing technical and scientific support.

Edited by: Michael Schulz

Reviewed by: two anonymous referees

\section{References}

Ångström, A.: The parameters of atmospheric turbidity, Tellus, 16, 64-75, https://doi.org/10.1111/j.2153-3490.1964.tb00144.x, 1964.

Albrecht, B. A.: Aerosols, cloud microphysics, and fractional cloudiness, Science, 245, 1227-1230, https://doi.org/10.1126/science.245.4923.1227, 1989.

Andersen, H., Cermak, J., Fuchs, J., and Schwarz, K.: Global observations of cloud-sensitive aerosol loadings in low-level marine clouds, J. Geophys. Res.-Atmos., 121, 12936-12946, https://doi.org/10.1002/2016JD025614, 2016.

Andersen, H., Cermak, J., Fuchs, J., Knutti, R., and Lohmann, U.: Understanding the drivers of marine liquid-water cloud occurrence and properties with global observations using neural networks, Atmos. Chem. Phys., 17, 9535-9546, https://doi.org/10.5194/acp-17-9535-2017, 2017.

Bellouin, N., Quaas, J., Morcrette, J.-J., and Boucher, O.: Estimates of aerosol radiative forcing from the MACC re-analysis, Atmos. Chem. Phys., 13, 2045-2062, https://doi.org/10.5194/acp13-2045-2013, 2013.
Bender, F. A.-M., Engström, A., and Karlsson, J.: Factors Controlling Cloud Albedo in Marine Subtropical Stratocumulus Regions in Climate Models and Satellite Observations, J. Climate, 29, 3559-3587, https://doi.org/10.1175/JCLI-D-15-0095.1, 2016.

Bennartz, R.: Global assessment of marine boundary layer cloud droplet number concentration from satellite, J. Geophys. Res., 112, D02201, https://doi.org/10.1029/2006JD007547, 2007.

Boucher, O. and Quaas, J.: Water vapour affects both rain and aerosol optical depth, Nat. Geosci., 6, 4-5, https://doi.org/10.1038/ngeo1692, 2012.

Boucher, O., Randall, D., Artaxo, P., Bretherton, C., Feingold, G., Forster, P., Kerminen, V.-M., Kondo, Y., Liao, H., Lohmann, U., Rasch, P., Satheesh, S. K., Sherwood, S., Stevens, B., and Zhang, X. Y.: 7. Clouds and Aerosols, Climate Change 2013 - The Physical Science Basis Working Group I Contribution to the Fifth Assessment Report of the Intergovernmental Panel on Climate Change, Working Group I Contribution to the Fifth Assessment Report of the Intergovernmental Panel on Climate Change, 571657, https://doi.org/10.1017/CBO9781107415324.016, 2013.

Brenguier, J.-L., Pawlowska, H., Schüller, L., Preusker, R., Fischer, J. and Fouquart, Y.: Radiative Properties of Boundary Layer Clouds: Droplet Effective Radius versus Number Concentration, J. Atmos. Sci., 57, 803-821, https://doi.org/10.1175/15200469(2000)057<0803:RPOBLC>2.0.CO;2, 2000.

Brinkop, B. and Roeckner, E.: Sensitivity of a general circulation model to parametrizations of cloud-turbulence interactions in the atmospheric boundary layer, Tellus, 47, 197-220, https://doi.org/10.1034/j.1600-0870.1995.t01-1-00004.x, 1995.

Carslaw, K. S., Lee, L. A., Reddington, C. L., Pringle, K. J., Rap, A., Forster, P. M., Mann, G. W., Spracklen, D. V., Woodhouse, M. T., Regayre, L. A., and Pierce, J. R.: Large contribution of natural aerosols to uncertainty in indirect forcing, Nature, 503, 67-71, https://doi.org/10.1038/nature12674, 2013.

Chen, Y.-C., Christensen, M. W., Stephens, G. L., and Seinfeld, J. H.: Satellite-based estimate of global aerosol-cloud radiative forcing by marine warm clouds, Nat. Geosci., 7, 643-646, https://doi.org/10.1038/ngeo2214, 2014.

Christensen, M. W., Chen, Y.-C., and Stephens, G. L.: Aerosol indirect effect dictated by liquid clouds, J. Geophys. Res.-Atmos., 121, 14636-14650, https://doi.org/10.1002/2016JD025245, 2016.

Christensen, M. W., Neubauer, D., Poulsen, C. A., Thomas, G. E., McGarragh, G. R., Povey, A. C., Proud, S. R., and Grainger, R. G.: Unveiling aerosol-cloud interactions - Part 1: Cloud contamination in satellite products enhances the aerosol indirect forcing estimate, Atmos. Chem. Phys., 17, 13151-13164, https://doi.org/10.5194/acp-17-13151-2017, 2017.

Croft, B., Lohmann, U., Martin, R. V., Stier, P., Wurzler, S., Feichter, J., Hoose, C., Heikkilä, U., van Donkelaar, A., and Ferrachat, S.: Influences of in-cloud aerosol scavenging parameterizations on aerosol concentrations and wet deposition in ECHAM5-HAM, Atmos. Chem. Phys., 10, 1511-1543, https://doi.org/10.5194/acp-10-1511-2010, 2010.

Dee, D. P., Uppala, S. M., Simmons, A. J., Berrisford, P., Poli, P., Kobayashi, S., Andrae, U., Balmaseda, M. A., Balsamo, G., Bauer, P., Bechtold, P., Beljaars, A. C. M., van de Berg, L., Bidlot, J., Bormann, N., Delsol, C., Dragani, R., Fuentes, M., Geer, A. J., Haimberger, L., Healy, S. B., Hersbach, H., Hölm, E. V., Isaksen, L., Kallberg, P., Köhler, M., Matricardi, M., McNally, 
A. P., Monge-Sanz, B. M., Morcrette, J.-J., Park, B.-K., Peubey, C., de Rosnay, P., Tavolato, C., Thépaut, J.-N., and Vitart, F.: The ERA-Interim reanalysis: configuration and performance of the data assimilation system., Q. J. Roy. Meteor. Soc., 137, 553-597, https://doi.org/10.1002/qj.828, 2011.

ESA (European Space Agency): AATSR Multimission land and sea surface data, version 2.1, NERC Earth Observation Data Centre, available at: http://catalogue.ceda.ac.uk/uuid/ 1d0c047ea3ced97cc7e988d7d286052a (last access: 20 October 2017), 2014.

Feingold, G., Eberhard, W. L., Veron, D. E., and Previdi, M.: First measurements of the Twomey indirect effect using ground-based remote sensors, Geophys. Res. Lett., 30, 1287, https://doi.org/10.1029/2002GL016633, 2003.

Feingold, G., McComiskey, A., Yamaguchi, T., Johnson, J. S., Carslaw, K. S., and Schmidt, K. S.: New approaches to quantifying aerosol influence on the cloud radiative effect, P. Natl. Acad. Sci. USA, 113, 5812-5819, https://doi.org/10.1073/pnas.1514035112, 2016.

Geil, K. L. and Zeng, X.: Quantitative characterization of spurious numerical oscillations in 48 CMIP5 models, Geophys. Res. Lett., 42, 5066-5073, https://doi.org/10.1002/2015GL063931, 2015.

Gettelman, A. and Morrison, H.: Advanced Two-Moment Bulk Microphysics for Global Models, Part I: Off-Line Tests and Comparison with Other Schemes, J. Climate, 28, 1268-1287, https://doi.org/10.1175/JCLI-D-14-00102.1, 2015.

Gettelman, A., Morrison, H., Santos, S., Bogenschutz, P., and Caldwell, P. M.: Advanced Two-Moment Bulk Microphysics for Global Models. Part II: Global Model Solutions and Aerosol-Cloud Interactions, J. Climate, 28, 1288-1307, https://doi.org/10.1175/JCLI-D-14-00103.1, 2015.

Ghan, S., Wang, M., Zhang, S., Ferrachat, S., Gettelman, A., Griesfeller, J., Kipling, Z., Lohmann, U., Morrison, H., Neubauer, D., Partridge, D. G., Stier, P., Takemura, T., Wang, H., and Zhang, K.: Challenges in constraining anthropogenic aerosol effects on cloud radiative forcing using present-day spatiotemporal variability, P. Natl. Acad. Sci. USA, 113, 5804-5811, https://doi.org/10.1073/pnas.1514036113, 2016.

Grandey, B. S. and Stier, P.: A critical look at spatial scale choices in satellite-based aerosol indirect effect studies, Atmos. Chem. Phys., 10, 11459-11470, https://doi.org/10.5194/acp-10-114592010, 2010.

Grandey, B. S., Gururaj, A., Stier, P., and Wagner, T. M.: Rainfall-aerosol relationships explained by wet scavenging and humidity, Geophys. Res. Lett., 41, 5678-5684, https://doi.org/10.1002/2014GL060958, 2014.

Gryspeerdt, E., Stier, P., and Grandey, B. S.: Cloud fraction mediates the aerosol optical depth-cloud top height relationship, Geophys. Res. Lett., 41, 3622-3627, https://doi.org/10.1002/2014GL059524, 2014.

Gryspeerdt, E., Stier, P., White, B. A., and Kipling, Z.: Wet scavenging limits the detection of aerosol effects on precipitation, Atmos. Chem. Phys., 15, 7557-7570, https://doi.org/10.5194/acp15-7557-2015, 2015.

Gryspeerdt, E., Quaas, J., and Bellouin, N.: Constraining the aerosol influence on cloud fraction, J. Geophys. Res.-Atmos., 121, 35663583, https://doi.org/10.1002/2015JD023744, 2016.

Gryspeerdt, E., Quaas, J., Ferrachat, S., Gettelman, A., Ghan, S., Lohmann, U., Morrison, H., Neubauer, D., Partridge,
D. G., Stier, P., Takemura, T., Wang, H., Wang M., and Zhang, K.: Constraining the instantaneous aerosol influence on cloud albedo, P. Natl. Acad. Sci. USA, 114, 4899-4904, https://doi.org/10.1073/pnas.1617765114, 2017.

Hollmann, R., Merchant, C. J., Saunders, R., Downy, C., Buchwitz, M., Cazenave, A., Chuvieco, E., Defourny, P., de Leeuw, G., Forsberg, R., Holzer-Popp, T., Paul, F., Sandven, S., Sathyendranath, S., van Roozendael M., and Wagner, W.: The ESA climate change initiative: satellite data records for essential climate variables, B. Am. Meteorol. Soc., 94, 1541-1552. https://doi.org/10.1175/BAMS-D-11-00254.1, 2013.

Hoose, C., Lohmann, U., Bennartz, R., Croft, B., and Lesins, G.: Global simulations of aerosol processing in clouds, Atmos. Chem. Phys., 8, 6939-6963, https://doi.org/10.5194/acp-8-69392008, 2008a.

Hoose, C., Lohmann, U., Stier, P., Verheggen, B., and Weingartner, E.: Aerosol processing in mixed-phase clouds in ECHAM5-HAM: Model description and comparison to observations, J. Geophys. Res., 113, D07210, https://doi.org/10.1029/2007JD009251, 2008b.

Khairoutdinov, M. and Kogan, Y.: A new cloud physics parameterization in a large-eddy simulation model of marine stratocumulus, Mon. Weather Rev., 128, 229-243, https://doi.org/10.1175/15200493(2000)128<0229:ANCPPI>2.0.CO;2, 2000.

King, M., Tsay, S. C., Platnick, S., Wang, M., and Liou., K. N.: Cloud retrieval algorithms for MODIS: Optical thickness, effective particle radius, and thermodynamic phase, Algorithm Theor. Basis Doc. ATBD-MOD-05, NASA Goddard Space Flight Cent., Greenbelt, Md, 1998.

Koren, I., Altaratz, O., Remer, L. A., Feingold, G., Martins, J. V., and Heiblum, R.: Reply to "Water vapour affects both rain and aerosol optical depth", Nat. Geosci., 6, 5-5, https://doi.org/10.1038/ngeo1693, 2013.

Lamarque, J.-F., Bond, T. C., Eyring, V., Granier, C., Heil, A., Klimont, Z., Lee, D., Liousse, C., Mieville, A., Owen, B., Schultz, M. G., Shindell, D., Smith, S. J., Stehfest, E., Van Aardenne, J., Cooper, O. R., Kainuma, M., Mahowald, N., McConnell, J. R., Naik, V., Riahi, K., and van Vuuren, D. P.: Historical (1850-2000) gridded anthropogenic and biomass burning emissions of reactive gases and aerosols: methodology and application, Atmos. Chem. Phys., 10, 7017-7039, https://doi.org/10.5194/acp-10-7017-2010, 2010.

Lenderink, G. and Holtslag, A. A. M.: Evaluation of the Kinetic Energy Approach for Modeling Turbulent Fluxes in Stratocumulus, Mon. Weather Rev., 128, 244-258, https://doi.org/10.1175/15200493(2000)128<0244:EOTKEA >2.0.CO;2, 2000.

Lin, H. and Leaitch, W. R.: Development of an in-cloud aerosol activation parameterization for climate modelling, in Proceedings of the WMO Workshop on Measurement of Cloud Properties for Forecasts of Weather, Air Quality and Climate, 328-335, World Meteorol. Organ., Geneva, 1997.

Liu, J. and Li, Z.: Estimation of cloud condensation nuclei concentration from aerosol optical quantities: influential factors and uncertainties, Atmos. Chem. Phys., 14, 471-483, https://doi.org/10.5194/acp-14-471-2014, 2014.

Lohmann, U. and Hoose, C.: Sensitivity studies of different aerosol indirect effects in mixed-phase clouds, Atmos. Chem. Phys., 9, 8917-8934, https://doi.org/10.5194/acp-9-8917-2009, 2009. 
Lohmann, U. and Lesins, G.: Comparing continental and oceanic cloud susceptibilities to aerosols, Geophys. Res. Lett., 30, 1791, https://doi.org/10.1029/2003GL017828, 2003.

Lohmann, U., Stier, P., Hoose, C., Ferrachat, S., Kloster, S., Roeckner, E., and Zhang, J.: Cloud microphysics and aerosol indirect effects in the global climate model ECHAM5-HAM, Atmos. Chem. Phys., 7, 3425-3446, https://doi.org/10.5194/acp-7-34252007, 2007.

McComiskey, A. and Feingold, G.: The scale problem in quantifying aerosol indirect effects, Atmos. Chem. Phys., 12, 1031-1049, https://doi.org/10.5194/acp-12-1031-2012, 2012.

Menon, S., Genio, A. D. D., Koch, D., and Tselioudis, G.: GCM Simulations of the Aerosol Indirect Effect: Sensitivity to Cloud Parameterization and Aerosol Burden, J. Atmos. Sci., 59, 692-713, https://doi.org/10.1175/15200469(2002)059<0692:GSOTAI>2.0.CO;2, 2002.

Nakajima, T., Higurashi, A., Kawamoto, K., and Penner, J. E.: A possible correlation between satellite-derived cloud and aerosol microphysical parameters, Geophys. Res. Lett., 28, 1171-1174, https://doi.org/10.1029/2000GL012186, 2001.

Neubauer, D., Lohmann, U., Hoose, C., and Frontoso, M. G.: Impact of the representation of marine stratocumulus clouds on the anthropogenic aerosol effect, Atmos. Chem. Phys., 14, 1199712022, https://doi.org/10.5194/acp-14-11997-2014, 2014.

Nordeng, T. E.: Extended versions of the convective parameterization scheme at ECMWF and their impact on the mean and transient activity of the model in the tropics, Technical Memorandum 206, European Centre for Medium-RangeWeather Forecasts, Reading, UK, available at: https://www.ecmwf.int/sites/default/files/elibrary/1994/11393extended-versions-convective-parametrization-scheme-ecmwfand-their-impact-mean-and-transient.pdf (last access: 30 October 2017), 41 pp., 1994.

Penner, J. E., Quaas, J., Storelvmo, T., Takemura, T., Boucher, O., Guo, H., Kirkevåg, A., Kristjánsson, J. E., and Seland, Ø.: Model intercomparison of indirect aerosol effects, Atmos. Chem. Phys., 6, 3391-3405, https://doi.org/10.5194/acp-6-3391-2006, 2006.

Popp, T., de Leeuw, G., Bingen, C., Brühl, C., Capelle, V., Chedin, A., Clarisse, L., Dubovik, O., Grainger, R., Griesfeller, J., Heckel, A., Kinne, S., Klüser, L., Kosmale, M., Kolmonen, P., Lelli, L., Litvinov, P., Mei, L., North, P., Pinnock, S., Povey, A., Robert, C., Schulz, M., Sogacheva, L., Stebel, K., Stein Zweers, D., Thomas, G., Tilstra, L.G., Vandenbussche, S., Veefkind, P., Vountas, M., and Xue, Y.: Development, Production and Evaluation of Aerosol Climate Data Records from European Satellite Observations (Aerosol_cci), Remote Sens., 8, 421, https://doi.org/10.3390/rs8050421, 2016.

Posselt, R. and Lohmann, U.: Introduction of prognostic rain in ECHAM5: design and single column model simulations, Atmos. Chem. Phys., 8, 2949-2963, https://doi.org/10.5194/acp-8-29492008, 2008.

Posselt, R. and Lohmann, U.: Sensitivity of the total anthropogenic aerosol effect to the treatment of rain in a global climate model, Geophys. Res. Lett., 36, L02805, https://doi.org/10.1029/2008GL035796, 2009.

Poulsen, C. A., Siddans, R., Thomas, G. E., Sayer, A. M., Grainger, R. G., Campmany, E., Dean, S. M., Arnold, C., and Watts, P. D.: Cloud retrievals from satellite data using optimal estima- tion: evaluation and application to ATSR, Atmos. Meas. Tech., 5, 1889-1910, https://doi.org/10.5194/amt-5-1889-2012, 2012.

Quaas, J., Boucher, O., and Lohmann, U.: Constraining the total aerosol indirect effect in the LMDZ and ECHAM4 GCMs using MODIS satellite data, Atmos. Chem. Phys., 6, 947-955, https://doi.org/10.5194/acp-6-947-2006, 2006.

Quaas, J., Boucher, O., Bellouin, N., and Kinne, S.: Satellite-based estimate of the direct and indirect aerosol climate forcing, J. Geophys. Res., 113, D05204, https://doi.org/10.1029/2007JD008962, 2008.

Quaas, J., Ming, Y., Menon, S., Takemura, T., Wang, M., Penner, J. E., Gettelman, A., Lohmann, U., Bellouin, N., Boucher, O., Sayer, A. M., Thomas, G. E., McComiskey, A., Feingold, G., Hoose, C., Kristjánsson, J. E., Liu, X., Balkanski, Y., Donner, L. J., Ginoux, P. A., Stier, P., Grandey, B., Feichter, J., Sednev, I., Bauer, S. E., Koch, D., Grainger, R. G., Kirkevåg, A., Iversen, T., Seland, Ø., Easter, R., Ghan, S. J., Rasch, P. J., Morrison, H., Lamarque, J.-F., Iacono, M. J., Kinne, S., and Schulz, M.: Aerosol indirect effects - general circulation model intercomparison and evaluation with satellite data, Atmos. Chem. Phys., 9, 8697-8717, https://doi.org/10.5194/acp-9-8697-2009, 2009.

Quaas, J., Stevens, B., Stier, P., and Lohmann, U.: Interpreting the cloud cover - aerosol optical depth relationship found in satellite data using a general circulation model, Atmos. Chem. Phys., 10, 6129-6135, https://doi.org/10.5194/acp-10-6129-2010, 2010.

Remer, L. A., Kaufman, Y. J., Tanré, D., Mattoo, S., Chu, D. A., Martins, J. V., Li, R.-R., Ichoku, C., Levy, R. C., Kleidman, R. G., Eck, T. F., Vermote, E., and Holben, B. N.: The MODIS aerosol algorithm, products, and validation, J. Atmos. Sci., 62, 947-973, https://doi.org/10.1175/JAS3385.1, 2005.

Roeckner, E., Buml, G., Bonaventura, L., Brokopf, R., Esch, M., Giorgetta, M., Hagemann, S., Kirchner, I., Kornblueh, L., Manzini, E., Rhodin, A., Schlese, U., Schulzweida, U., and Tompkins, A.: The Atmospheric General Circulation Model ECHAM5: Part 1. REPORT 349, Tech. rep., Max Planck Institute for Meteorology Hamburg, Germany, 2003.

Rosenfeld, D., Chemke, R., Prather, K., Suski, K., Comstock, J. M., Schmid, B., Tomlinson, J., and Jonsson, H.: Polluting of winter convective clouds upon transition from ocean inland over central California: Contrasting case studies, Atmos. Res., 135, 112-127, https://doi.org/10.1016/j.atmosres.2013.09.006, 2014.

Rotstayn, L. D. and Liu, Y.: A smaller global estimate of the second indirect aerosol effect, Geophys. Res. Lett., 32, L05708, https://doi.org/10.1029/2004GL021922, 2005.

Sant, V., Lohmann, U., and Seifert, A.: Performance of a triclass parameterization for the collision-coalescence process in shallow clouds, J. Atmos. Sci., 70, 1744-1767, https://doi.org/10.1175/JAS-D-12-0154.1, 2013.

Sant, V., Posselt, R., and Lohmann, U.: Prognostic precipitation with three liquid water classes in the ECHAM5-HAM GCM, Atmos. Chem. Phys., 15, 8717-8738, https://doi.org/10.5194/acp15-8717-2015, 2015.

Schmidt, J., Ansmann, A., Bühl, J., and Wandinger, U.: Strong aerosol-cloud interaction in altocumulus during updraft periods: lidar observations over central Europe, Atmos. Chem. Phys., 15, 10687-10700, https://doi.org/10.5194/acp-15-106872015, 2015.

Schutgens, N. A. J., Partridge, D. G., and Stier, P.: The importance of temporal collocation for the evaluation of aerosol mod- 
els with observations, Atmos. Chem. Phys., 16, 1065-1079, https://doi.org/10.5194/acp-16-1065-2016, 2016.

Stephens, G. L., Vane, D. G., Tanelli, S., Im, E., Durden, S., Rokey, M., Reinke, D., Partain, P., Mace, G. G., Austin, R., L'Ecuyer, T., Haynes, J., Lebsock, M., Suzuki, K., Waliser, D., Wu, D., Kay, J., Gettelman, A., Wang, Z., and Marchand, R.: CloudSat mission: Performance and early science after the first year of operation, J. Geophys. Res., 113, D00A18, https://doi.org/10.1029/2008JD009982, 2008.

Shinozuka, Y., Clarke, A. D., Nenes, A., Jefferson, A., Wood, R., McNaughton, C. S., Ström, J., Tunved, P., Redemann, J., Thornhill, K. L., Moore, R. H., Lathem, T. L., Lin, J. J., and Yoon, Y. J.: The relationship between cloud condensation nuclei (CCN) concentration and light extinction of dried particles: indications of underlying aerosol processes and implications for satellitebased CCN estimates, Atmos. Chem. Phys., 15, 7585-7604, https://doi.org/10.5194/acp-15-7585-2015, 2015.

Stevens, B. and Feingold, G.: Untangling aerosol effects on clouds and precipitation in a buffered system, Nature, 461, 607-613, https://doi.org/10.1038/nature08281, 2009.

Stevens, B., Moeng, C.-H., and Sullivan, P. S.: Large-Eddy Simulations of Radiatively Driven Convection: Sensitivities to the Representation of Small Scales, J. Atmos. Sci., 56, 3963-3984, https://doi.org/10.1175/15200469(1999)056<3963:LESORD>2.0.CO;2, 1999.

Stevens, B., Giorgetta, M., Esch, M., Mauritsen, T., Crueger, T., Rast, S., Salzmann, M., Schmidt, H., Bader, J., Block, K., Brokopf, R., Fast, I., Kinne, S., Kornblueh, L., Lohmann, U., Pincus, R., Reichler, T., and Roeckner, E.: Atmospheric component of the MPI-M Earth System Model: ECHAM6, J. Adv. Model. Earth Syst., 5, 146-172, https://doi.org/10.1002/jame.20015, 2013.

Stier, P.: Limitations of passive remote sensing to constrain global cloud condensation nuclei, Atmos. Chem. Phys., 16, 6595-6607, https://doi.org/10.5194/acp-16-6595-2016, 2016.

Stier, P., Feichter, J., Kinne, S., Kloster, S., Vignati, E., Wilson, J., Ganzeveld, L., Tegen, I., Werner, M., Balkanski, Y., Schulz, M., Boucher, O., Minikin, A., and Petzold, A.: The aerosol-climate model ECHAM5-HAM, Atmos. Chem. Phys., 5, 1125-1156, https://doi.org/10.5194/acp-5-1125-2005, 2005.

Suzuki, K., Stephens, G., van den Heever, S., and Nakajima, T.: Diagnosis of the warm rain process in cloud-resolving models using joint CloudSat and MODIS observations. J. Atmos. Sci., 68, 2655-2670, 2011.

Suzuki, K., Golaz, J.-C., and Stephens, G. L.: Evaluating cloud tuning in a climate model with satellite observations, Geophys. Res. Lett., 40, 4464-4468, https://doi.org/10.1002/grl.50874, 2013.

Textor, C., Schulz, M., Guibert, S., Kinne, S., Balkanski, Y., Bauer, S., Berntsen, T., Berglen, T., Boucher, O., Chin, M., Dentener, F., Diehl, T., Easter, R., Feichter, H., Fillmore, D., Ghan, S., Ginoux, P., Gong, S., Grini, A., Hendricks, J., Horowitz, L., Huang, P., Isaksen, I., Iversen, I., Kloster, S., Koch, D., Kirkevåg, A., Kristjansson, J. E., Krol, M., Lauer, A., Lamarque, J. F., Liu, X., Montanaro, V., Myhre, G., Penner, J., Pitari, G., Reddy, S., Seland, Ø., Stier, P., Takemura, T., and Tie, X.: Analysis and quantification of the diversities of aerosol life cycles within AeroCom, Atmos. Chem. Phys., 6, 1777-1813, https://doi.org/10.5194/acp-6-17772006, 2006.
Thomas, G. E., Poulsen, C. A., Sayer, A. M., Marsh, S. H., Dean, S. M., Carboni, E., Siddans, R., Grainger, R. G., and Lawrence, B. N.: The GRAPE aerosol retrieval algorithm, Atmos. Meas. Tech., 2, 679-701, https://doi.org/10.5194/amt-2-679-2009, 2009.

Tiedtke, M.: A Comprehensive Mass Flux Scheme for $\mathrm{Cu}$ mulus Parameterization in Large-Scale Models, Mon. Weather Rev., 117, 1779-1800, https://doi.org/10.1175/15200493(1989)117<1779:ACMFSF>2.0.CO;2, 1989.

Twomey, S.: Pollution and the planetary albedo, Atmos. Environ., 8, 1251-1256, https://doi.org/10.1016/0004-6981(74)90004-3, 1974.

Twohy, C. H., Coakley Jr., J. A., and Tahnk, W. R.: Effect of changes in relative humidity on aerosol scattering near clouds, J. Geophys. Res., 114, D05205, https://doi.org/10.1029/2008JD010991, 2009.

Varnái, T. and Marshak, A.: MODIS observations of enhanced clear sky reflectance near clouds, Geophys. Res. Lett., 36, 106807, https://doi.org/10.1029/2008GL037089, 2009.

Zeng, S., Riedi, J., Trepte, C. R., Winker, D. M., and Hu, Y.-X.: Study of global cloud droplet number concentration with A-Train satellites, Atmos. Chem. Phys., 14, 7125-7134, https://doi.org/10.5194/acp-14-7125-2014, 2014.

Zhang, K., O'Donnell, D., Kazil, J., Stier, P., Kinne, S., Lohmann, U., Ferrachat, S., Croft, B., Quaas, J., Wan, H., Rast, S., and Feichter, J.: The global aerosol-climate model ECHAM-HAM, version 2: sensitivity to improvements in process representations, Atmos. Chem. Phys., 12, 8911-8949, https://doi.org/10.5194/acp-12-8911-2012, 2012.

Zhao, G., Zhao, C., Kuang, Y., Tao, J., Tan, W., Bian, Y., Li, J., and $\mathrm{Li}, \mathrm{C}$.: Impact of aerosol hygroscopic growth on retrieving aerosol extinction coefficient profiles from elasticbackscatter lidar signals, Atmos. Chem. Phys., 17, 12133-12143, https://doi.org/10.5194/acp-17-12133-2017, 2017.

Zygmuntowska, M., Mauritsen, T., Quaas, J., and Kaleschke, L.: Arctic Clouds and Surface Radiation - a critical comparison of satellite retrievals and the ERA-Interim reanalysis, Atmos. Chem. Phys., 12, 6667-6677, https://doi.org/10.5194/acp-126667-2012, 2012. 